\title{
Basal resource quality and energy sources in three habitats of a lowland
}

\section{river ecosystem}

Paul J. McInerney ${ }^{1,7^{*}}$, Galen Holt ${ }^{2}$, Rebecca E. Lester ${ }^{2}$, Ross M. Thompson ${ }^{3}$, Barbara Robson ${ }^{4}$, Darren

S. Ryder ${ }^{5}$, Nick R. Bond ${ }^{6}$, Darren S. Baldwinn ${ }^{7}$ Ben Gawne ${ }^{8}$, and Rochelle Petrie ${ }^{6}$.

${ }^{*}$ Corresponding author

${ }^{1}$ CSIRO, Land and Water, Thurgoona, NSW, Australia

paul.mcinerney@csiro.au

${ }^{2}$ Centre for Regional and Rural Futures, Deakin University, Geelong, Victoria, Australia,

g.holt@deakin.edu.au, rebecca.lester@deakin.edu.au

${ }^{3}$ Centre for Applied Water Science, University of Canberra, Canberra, Australian Capital Territory, Australia, ross.thompson@canberra.edu.au

${ }^{4}$ Australian Institute of Marine Science, and AIMS@JCU, Townsville, Australia, b.robson@aims.gov.au

${ }^{5}$ School of Environmental and Rural Science, University of New England, Armidale, New South Wales, Australia, dryder2@une.edu.au

${ }^{6}$ Centre for Freshwater Ecosystems, La Trobe University, Wodonga, Victoria, Australia n.bond@latrobe.edu.au, r.petrie@latrobe.edu.au

This is the author manuscript accepted for publication and has undergone full peer review but has not been through the copyediting, typesetting, pagination and proofreading process, which may lead to differences between this version and the Version of Record. Please cite this article as doi: 10.1002/lno.11548

This article is protected by copyright. All rights reserved. 
${ }^{7}$ Institute of Land Water and Society, Charles Sturt University, Thurgoona NSW Australia, dbaldwin@csu.edu.au

${ }^{8}$ Murray-Darling Basin Authority, Canberra, Australian Capital Territory, Australia, ben.gawne@mdba.gov.au

Running Head: Energy sources in a lowland river food web

Keywords: Essential fatty acids, seston, basal energy, food web, lowland river, stable isotopes, wetlands, floodplain, anabranches, PUFA 


\section{Abstract}

Understanding energy flow through ecosystems and among sub-habitats is critical for understanding patterns of biodiversity and ecosystem function. It can also be of considerable applied interest in situations where managing for connectivity among habitats is important for restoring degraded ecosystems. Here, we describe patterns of basal resource quality and identify primary basal energy sources in three habitats - river channels, anabranches and wetlands - of a lowland river floodplain in the Murray River catchment, Australia during a period of disconnected surface flow. We used a combination of stable isotope and fatty acid analyses to determine which basal resources were assimilated by the backswimmer Anisops thienemanni and the Eastern mosquitofish Gambusia holbrooki and assessed food quality across the three habitats. Seston was a primary basal resource for both animals in all three habitats, but was of higher quality within floodplain habitats than in the river channel. Although floodplain seston contained higher concentrations of essential fatty acids, fatty acid profiles of animals from different habitats remained similar. Our research suggests that inundation of floodplains and subsequent reconnection to the river could be valuable to afford riverine animals the opportunity to access high quality resources, but highlights a need to quantitatively assess the transfer of essential fatty acids between trophic levels to determine how much riverine animals are in fact limited by poorer quality food resources. We demonstrate the importance of estimating the quality of organic matter fluxes into food webs, and the potential role of targeted environmental flows to reestablish high quality energy pathways in riverine ecosystems. 


\section{Introduction}

Food webs represent an important facet of ecosystem function and describe the energy pathways between resources and animals (Hladyz et al. 2012). Within freshwater ecosystems, research has focused on understanding the contribution and importance of terrestrially-and aquatically-derived carbon to food webs (e.g. Rees et al. 2020). Less attention has been oriented towards determining the quality of food resources (e.g. Guo et al. 2018) and the dominant pathways for energy to reach higher trophic levels. Understanding which resources underpin food webs and factors influencing resource availability to animals is key to improving our capacity to gauge ecosystem health (Holland et al. 2020).

Food quality, in its coarsest form, may be assessed by ecological stoichiometry (e.g. C:N) however, animals can be limited by availability of complex organic compounds such as amino acids (Dwyer et al. 2018), sterols and fatty acids (Twining et al. 2016). Within freshwater ecosystems, algae and, in particular, diatoms are considered high-quality food resources for herbivorous taxa due to their high concentration of inorganic nutrients (nitrogen and phosphorous) and long-chain polyunsaturated fatty acids (e.g Guo et al. 2018). Some omega-3 ( $\omega 3)$ and omega- 6 ( $\omega 6)$ polyunsaturated fatty acids, such

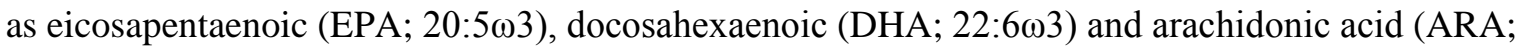
20:4ஸ6) are essential for physiological functions of animals (e.g. somatic growth and reproduction, Sargent et al. 1999). These compounds, often referred to as essential fatty acids, are not able to be synthesized by animals de novo, and must be either sourced from their diet (Parrish 2009) or synthesized from shorter-chain polyunsaturated fatty acids, such as alpha-linolenic (ALA; 18:303)

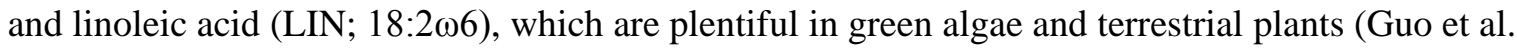
2017). Gaining a better understanding of the spatial and temporal distribution and availability of longchain polyunsaturated fatty acids within floodplain landscapes is important for assessing potential effects of resource deficiencies on higher animals, such as fish and water birds. 
Traditionally, ecologists have used stable isotope values to trace energy patterns in food webs (e.g. Giling et al. 2009), but this approach can have limitations when potential dietary sources have similar values (e.g. terrestrial litter, bacteria, seston) leading to difficulty in discriminating between pathways. As such, other diet-specific markers are increasingly used to help understand the relationship between resources and animals and the flow of material through food webs (e.g. Growns et al. 2020). The biomarkers selected are, preferably, unique to a particular food resource, easily determined and metabolically stable however, meeting all of these conditions concurrently is rare (Taipale et al. 2011). Fatty acid composition can meet several of these criteria and has been widely used in both marine and freshwater food webs to trace energy pathways and to unravel trophic dynamics (Brett et al. 2009). Combining fatty acids with more traditional stable isotope biomarkers shows promise for improving diet estimates, particularly in underdetermined systems (i.e., more sources than biomarkers, O'Donovan et al. 2018).

River-floodplain connectivity strongly influences the productivity and energy dynamics of aquatic ecosystems (Humphries et al. 2014), but the specific role of floodplain wetlands and inter-connecting channels in supplying essential food elements to river animals is less well understood. Temperate fish species may exploit inundated floodplain habitats and exhibit increased rates of somatic growth compared with growth in non-flood years (Gutreuter et al. 1999). In addition, fish productivity has been positively related to flood volume and flooding extent (Beesley et al. 2012). Terrestrially-derived carbon and nutrients released from sediments following floodplain inundation can increase aquatic invertebrate consumer biomass (e.g. McInerney et al. 2017), but the pathways by which animals receive organic molecules that are critical for disease resistance, development of neural tissues, reproduction and optimum somatic growth are not well understood for freshwater animals.

Connectivity between floodplain and riverine habitats has become of profound applied interest as hydrology in the vast majority of rivers globally has been heavily modified. Many hydrologically- 
modified rivers are characterized by reduced connectivity to floodplain habitats, with impacts on fisheries, floodplain productivity and ecosystem processes. Environmental flows, defined by the Brisbane Declaration (2007) as "the quantity, timing, and quality of water flows required to sustain freshwater and estuarine ecosystems and the human livelihoods and well-being that depend on these ecosystems”, are increasingly used by managers to support resilience within aquatic ecosystems under dynamic and variable hydrological scenarios. The use of environmental flows to restore aspects of the hydrologic regime that promote floodplain-river connectivity has become a management focus globally. In some locations manufactured infrastructure is used to restore river and floodplain habitats in place of relying on natural overbank floods. However, effectively managing these linkages requires a more detailed understanding of which basal resources are most important for animals and how basal resource quality might be improved by targeting specific floodplain and riverine habitats with environmental flows.

Here we use the ratios of stable isotopes of $\mathrm{C}\left(\delta^{13} \mathrm{C}\right)$ and $\mathrm{N}\left(\delta^{15} \mathrm{~N}\right)$ and fatty acid biomarkers to reveal primary energy pathways from basal resources to animals and patterns of high- and low-quality food resources within three habitats of a lowland temperate Australian river: (1) river channels, (2) anabranches and (3) wetlands. We expected that planktonic organic matter sources in the water column (i.e. seston) would be a dynamically controlling basal food resource for aquatic animals (Hladyz et al. 2012). In light of inundation responses of aquatic invertebrates (e.g. increased biomass McInerney et al. 2017) and fish (e.g. increased recruitment and body condition - Beesley et al. 2012) inhabiting floodplains, we hypothesized that wetland and anabranch habitats would sustain higher concentrations of dissolved organic carbon (leached from floodplain litter) and planktonic algae within the water column than river habitats. Subsequently, we expected that wetland and anabranch seston would supply higher concentrations of essential fatty acids for animals than seston in the river channel. 


\section{Methods}

\section{Sites}

Sampling was conducted within the Murray-Darling Basin, which drains one-seventh of the Australian land mass (Figure 1). Sites were located on the Ovens River floodplain near Peechelba in north east Victoria. The Ovens is a relatively unregulated river (with two small reservoirs in its 7780$\mathrm{km}^{2}$ catchment - Lake Buffalo and Lake William Hovell), and only $3 \%$ of its water is diverted for irrigation. As such, the flow regime is relatively natural and the floodplain at Peechelba is usually inundated annually in spring by natural flow spates, although floodplain inundation can occur at any time of year following significant rain events in the upper catchment. During high flows, the river is connected to the floodplain by a network of anabranches which inundate dry sections of the floodplain and connect (or fill) numerous temporary and semi-permanent wetlands. During low-flow periods in summer and autumn, anabranches and wetlands accumulate dried leaf litter and large woody debris, and thus facilitate ready exchange of terrestrial organic matter from the floodplain to the main river channel when hydrologic connection is reinstated (Hladyz et al. 2012). Terrestrial litter transferred to aquatic ecosystems is supplied by a dense overstorey of River red gum Eucalyptus camaldulensis, with stands of River bottlebrush Callistemon sieberi adjacent to waterways. The understorey is also densely covered by a mixture of exotic and native grasses, with Slender knotweed Persicaria decipiens and Common reed Phragmites australis dominant along the margins of waterways. Food webs were sampled from three habitat types (i.e. river channel, anabranches and permanent wetlands) in the austral summer of 2017 (Figure 1, Table S1). Samples were collected from three replicate sites of each habitat type (9 sites in total), approximately 8 weeks after a floodplain inundation event such that, at the time of sampling, wetlands had been disconnected from anabranches 
and the river channel for approximately 7 weeks and anabranches had been disconnected from the river channel for approximately 4 weeks.

\section{Sample preparation and analyses}

We measured water quality at three randomly-selected locations within each site. We collected all water-quality samples between 1000 and $1400 \mathrm{~h}$ to minimize temporal confounding of spatial patterns. We recorded temperature, conductivity, $\mathrm{pH}$, dissolved $\mathrm{O}_{2}$, and turbidity at each location with a Hydrolab Quanta multiprobe (OTT Messtechnik, Kempten, Germany). We also collected water samples from each location to measure dissolved organic carbon and chlorophyll-a (see Appendix S1 for analysis of water samples).

Terrestrial and benthic litter, macrophytes (both emergent e.g. P. australis, Myriophyllum papillosum and submerged e.g. Potamageton sulcatus), biofilm, periphyton, seston, benthic and planktonic zooplankton (predominantly Copepoda, Rotifera and Cladocera), the predatory waterbug Anisops thienemanni and the invasive mosquitofish Gambusia holbrooki were collected for carbon and nitrogen stable isotope analyses (Hladyz et al. 2012) and fatty acid profiles (Conlan et al. 2017). Anisops thienemanni and G. holbrooki were chosen because previous studies (e.g. Ho et al. 2011) have established them as apex predators within wetland and anabranch habitats and because they occur among all habitats, although unfortunately in the present study, the latter taxa was not obtained from the river channel. For litter, macrophytes, biofilm and periphyton, samples were frozen immediately following collection in the field $\left(-20^{\circ} \mathrm{C}\right)$. For seston, three replicate water samples were collected and filtered through sieves (53 $\mu \mathrm{m}$ to remove zooplankton) before being filtered onto quartz filters until clogged, prior to freezing. Zooplankton were sampled using a 12 -volt submersible inline pump with a pumping capacity of $25 \mathrm{~L} \mathrm{~min}^{-1}$ before immediate freezing $\left(-20^{\circ} \mathrm{C}\right)$. Benthic zooplankton were collected by moving the pump intake approximately $5 \mathrm{~cm}$ above the benthos, and planktonic zooplankton were collected from the water column approximately $10-30 \mathrm{~cm}$ below the 
water surface. Zooplankton were later manually removed from bulk samples in the laboratory.

Anisops thienemanni and G. holbrooki were collected from the littoral zone by sweep netting (250- $\mu \mathrm{m}$ mesh sweep net with a D-opening of $300 \times 300 \mathrm{~mm}$ ). Whole benthic and planktonic invertebrates and muscle from G. holbrooki were dried and ground to a fine powder prior to analyses.

For stable isotope analyses, all samples (excluding terrestrial litter, since we sampled benthic litter directly, and zooplankton because insufficient material was collected to complete all planned analyses) were weighed into tin-foil capsules and combusted in a Europa ANCA-GSL mass spectrometer fitted with a Sercon 20-22 IRMS stable isotope analyzer (precision (1 SD): $\delta^{13} \mathrm{C}=0.10$ $\%$, $\delta^{15} \mathrm{~N}=0.20 \%$ and $\mathrm{C} / \mathrm{N}$ ratio $=0.1$ ) without acidification (Europa Ltd., Crewe, U.K.). All isotope values are given in per mil (\%o), and standard $\delta$ notation is used to describe the relative difference in isotope ratio between the samples and a known standard (Vienna Pee Dee belemnite). For fatty acid profiles, methods followed those used by Conlan et al. (2017) and for all freeze-dried samples lipid was extracted from dry samples soaked in dichloromethane:methanol $\left(\mathrm{CH}_{2} \mathrm{Cl}_{2}: \mathrm{CH}_{3} \mathrm{OH}\right)$ and quantified gravimetrically on a 4-figure balance. Lipid class analysis used an Iatroscan MK $6 \mathrm{~s}$ thin layer chromatography-flame ionization detector. Fatty acids were then extracted and esterified into methyl esters using the acid catalyzed methylation method (Christie 2003). Following Conlan et al. (2017), fatty acid methyl esters were identified using an Agilent Technologies 7890A GC System (Agilent Technologies; Santa Clara, CA, USA) equipped with a BPX70 capillary column (120 m × $0.25 \mathrm{~mm}$ internal diameter, $0.25 \mu \mathrm{m}$ film thickness, SGE Analytical Science, Ringwood, VIC, Australia), a flame ionization detector, an Agilent Technologies 7693 auto sampler, and a splitless injection system. Each fatty acid was identified relative to known external standards (Sigma-Aldrich, Inc., St. Louis, MO, USA and Nu-Chek Prep Inc., Elysian, MN, USA), using GC ChemStation (Rev B.04.03; Agilent Technologies; Santa Clara, CA, USA). 


\section{Statistical analysis}

All univariate and multivariate models had the same general form. We used 2-factor analyses (fixed factors: habitat and identity) primarily to identify differences in isotopic values and fatty acid profiles of basal resources and animals among habitats. We used three habitat levels (river channel, anabranch and wetland) and levels for identity varied for isotopic and fatty acid analyses. For isotopic analyses, we used five source identity levels (periphyton, benthic litter, biofilm, macrophytes and seston) and two consumer identity levels (A. thienemanni and G. holbrooki) and, for fatty acid profiles, we used six source identity levels and four consumer identity levels (i.e. terrestrial litter and planktonic and benthic zooplankton were included for fatty acid analyses). We used permutational analysis of variance (PERMANOVA) in PRIMER v7 (Plymouth Marine Laboratories, 2015) to test for differences in all univariate and multivariate response variables among treatments. All fatty acid percentage data was logit transformed (Warton and Hui 2011) to meet the assumption of a normal distribution before analyses.

We estimated the relative importance of four trophic sources (biofilm, benthic litter, macrophytes and seston - periphyton was not obtained from all sites and could not be included) to the diets of $A$. thienemanni and G. holbrooki using mixing models implemented in the MixSIAR package in $\mathrm{R}$ (Stock and Semmens 2016a). The MixSIAR package takes a Bayesian approach to estimate a multivariate probability distribution for the consumer's diet composition. Dietary mixing models are underdetermined when the number of sources exceeds $1+$ the number of tracers, and so for our situation with four sources a mixing model with only the two stable isotopes $\delta 13 \mathrm{C}$ and $\delta 15 \mathrm{~N}$ yields highly uncertain estimates (Figure A4, Appendix S2). We therefore improved our estimates by incorporating our matching fatty acid data in a combined dataset, which has shown promise in other underdetermined systems (e.g. O'Donovan et al. 2018). Previous work sampled large-bodied organisms for both animals and prey and so had matched stable isotope and fatty acid samples. In 
contrast, our stable isotope and fatty acid samples are not exactly matched, and so we cannot use the raw data, but instead use the means and variance of each tracer for each group. This approach discards information in the covariances between tracers but allows them to be considered simultaneously. A similar but novel approach that retains the covariances in the raw data by using stable isotope estimates as a prior for a fatty acid model is discussed in the supplement to provide multiple lines of evidence for our findings.

In addition to the stable isotopes $\delta^{13} \mathrm{C}$ and $\delta^{15} \mathrm{~N}$, we included essential fatty acids (20:5 $\omega 3,20: 4 \omega 6$, 18:2 $\omega 6$, and $18: 3 \omega 3)$ and $18: 1 \omega 7$ as tracers because of their contributions to biological processes and inability to be synthesised (Sargent et al. 1999). We did not include DHA in this set of essential fatty acids, since some teleost fish are capable of DHA biosynthesis (e.g. Oboh et al. 2017). The monounsaturated fatty acid 18:1@7, a recognised bacterial biomarker (Guo et al. 2018), was included to increase our capacity to resolve litter and biofilm from seston and macrophytes. An alternative would be to choose the fatty acids statistically rather than mechanistically, which we address in the supplementary material (Appendix S2) to provide multiple lines of evidence for the robustness of our findings.

The probability distributions for diet composition produced by MixSIAR account for variation in source and consumer values, as well as variation in the trophic discrimination factor. Our MixSIAR model included both residual and process error, to account for variation in consumer values arising from both consumer sampling from a variable source distribution and variation among consumer individuals in digestion, assimilation, or metabolism (Stock and Semmens 2016b). We used a mean per-trophic-level discrimination factor of $0.4 \%$ for $\delta^{13} \mathrm{C}$ and $2.3 \%$ for $\delta^{15} \mathrm{~N}$, with standard deviations of $1.20 \%$ and $1.61 \%$, respectively, obtained from (Hladyz et al. 2012; McCutchan Jr et al. 2003). We assumed that both A. thienemanni and G. holbrooki were two trophic levels above the producers and so we multiply the means and variances of the discrimination distributions by 2, yielding realized total 
mean trophic discrimination factors of $0.8 \%$ for $\delta^{13} \mathrm{C}$ and $4.6 \%$ for $\delta^{15} \mathrm{~N}$, with standard deviations of $1.70 \%$ and $2.27 \%$, respectively. The presence of an intervening trophic level means that the diet compositions discussed here are not the direct contributions of the producers to the consumer diet. Instead, they are the contributions of each primary producer to the somatic makeup of the animals. Trophic discrimination factors are not available for the species in question, and so we follow O'Donovan et al. (2018) in using discrimination factors from a trophically similar species, in our case round goby (Neogobius melanostomus) fed on a diet of Mysis, obtained from Happel et al. (2016), with more detail provided in Appendix S2.

The MixSIAR model was run with 4 chains of length 1,500,000, with burn in of 750,000, and thinning every $500^{\text {th }}$ iteration. Convergence of the model was assessed using Gelman-Rubin and Geweke diagnostics (provided in supplement), as well as visual examination of trace plots. To test for diet composition differences between animals and among habitats, we conducted model comparisons using leave one out cross validation (Stock et al. 2018). We compared a null model with all data pooled to a model with consumer species included as a factor, a model with habitat included (but not consumer), and a model with both consumer and habitat as factors. We then performed secondary model comparisons within consumer species to provide more direct tests of how the diets of A. thienemanni and G. holbrooki might differ among habitats. These tests compared withinconsumer null models with within-consumer models including habitat as a factor. For fatty acid profiles we aggregated fatty acids into eight classes, representing essential fatty acids and important fatty acid functional groups; saturated fatty acids, monounsaturated fatty acids, polyunsaturated essential fatty acids (LIN, ALA, ARA, EPA and DHA) and bacterial fatty acids. Bacterial fatty acids included 10:0 2-OH, 15:0, 17:0 and their branched iso- and anteiso-homologues and 18:1 $\omega 7$ (Guo et al. 2018). Fatty acid functional groups for sources and animals were analyzed together with principal component analysis using PRIMER to visualize differences in fatty acid 
profiles (version 7; Anderson 2005). We used univariate PERMANOVA to analyze trends in isotopic values of $\delta^{13} \mathrm{C}$ and $\delta^{15} \mathrm{~N}$ and for comparisons of individual fatty acids among habitats. For all univariate analyses, we carried out tests of significance with the randomization routines in PERMANOVA, after estimating Euclidean distances among samples (Anderson et al. 2008). For all significance tests—-both univariate and multivariate—-we estimated Monte-Carlo $p$-values because of the relatively low number of possible permutations for tests of certain model terms (Anderson et al. 2008). We used SIMPER (Clarke 1993) to measure similarity of whole fatty acid profiles among sources and animals and to compare dissimilarity among habitats.

\section{Results}

\section{Water Quality}

All measures of water quality, dissolved organic carbon and chlorophyll- $a$ differed significantly among our three habitats PERMANOVA, Table S2). Mean water temperature was highest in wetlands $\left(25.44 \pm 0.30{ }^{\circ} \mathrm{C}\right)$ and lowest in anabranches $\left(22.80 \pm 0.46^{\circ} \mathrm{C}\right)$. Mean electrical conductivity was similar between the river channel and wetlands ( $0.07 \pm 0.00$ and $0.12 \pm 0.01 \mathrm{mScm}^{-1}$, respectively), but was elevated within anabranches $\left(0.49 \pm 0.20 \mathrm{mScm}^{-1}\right)$. Mean $\mathrm{pH}$ values between habitats were similar, ranging between $6.48 \pm 0.05$ and $6.72 \pm 0.09$. Mean dissolved $\mathrm{O}_{2}$ and turbidity displayed similar patterns between habitats and were highest in the river channel $\left(6.64 \pm 0.04 \mathrm{mgL}^{-1}\right.$ and $19.60 \pm$ 1.69 NTU, respectively), intermediate in anabranches $\left(2.56 \pm 0.67 \mathrm{mgL}^{-1}\right.$ and $14.68 \pm 1.36 \mathrm{NTU}$, respectively) and lowest in wetlands (2.08 $\pm 0.64 \mathrm{mgL}^{-1}$ and $10.23 \pm 1.83 \mathrm{NTU}$, respectively). Mean concentration of dissolved organic carbon was highest in wetlands $\left(17.23 \pm 6.14 \mathrm{mg} \mathrm{CL}^{-1}\right)$, intermediate in anabranches $\left(8.17 \pm 0.97 \mathrm{mg} \mathrm{CL}^{-1}\right)$ and lowest in the river channel $(4.72 \pm 0.15 \mathrm{mg}$ $\mathrm{CL}^{-1}$ ). Mean chlorophyll- $a$ concentration paralleled dissolved organic carbon, with values ranging 
from $41.50 \pm 5.02 \mu \mathrm{gL}^{-1}$ in wetlands, $36.75 \pm 2.41 \mu \mathrm{gL}^{-1}$ in anabranches and $17.75 \pm 2.82 \mu \mathrm{gL}^{-1}$ in the river channel.

\section{Stable Isotopes}

Delta ${ }^{15} \mathrm{~N}$ values for both sources and animals differed among habitats $\left(P s e u d o-F_{2,39}=6.78, P=\right.$ 0.005 ) and identity (Pseudo $-F_{4,39}=9.29, P=0.001$, Table 1 ). Among sources, mean $\delta^{15} \mathrm{~N}$ values were lowest in wetland benthic litter $(1.36 \pm 0.43 \%$ ) and ranged from $3.53 \pm 0.93 \%$ in wetland seston to $6.64 \pm 0.32 \%$ in river biofilms (Figure 2). G. holbrooki collected from anabranches displayed the highest $\delta^{15} \mathrm{~N}$ values among animals (11.30 $\pm 0.18 \%$ ), while the lowest values were recorded from wetland A. thienemanni $(7.65 \pm 0.23 \%)$. Mean values for $\delta^{13} \mathrm{C}$ of sources were similar among our three habitats, but differed among identity $\left(P=0.001\right.$, Pseudo $-F_{4,39}=9.79$, Table 1$)$. Values for $\delta^{13} \mathrm{C}$ for all animals were similar (-31.67 \pm 1.20 to $-35.11 \pm 0.67 \%$ ). Mean $\delta^{13} \mathrm{C}$ values were lowest in seston in anabranches $(-36.95 \pm 0.51 \%)$ and wetlands $(-35.50 \pm 0.57 \%$ ) and highest within wetland macrophytes (-24.40 $\pm 1.41 \%$ ). Mean $\delta^{13} \mathrm{C}$ values for aquatic seston and biofilm displayed the same general pattern among habitats, with samples collected from anabranches lowest, wetlands intermediate and river channel highest (Figure 2).

The MixSIAR Bayesian mixing models showed that seston was the dominant carbon source for both consumer species in all habitats (Figure 3), although there is overlap between seston and litter for $A$. thienemanni in wetlands at the $90 \%$ credible interval (CI) (numerical ranges supplied; Table A3, Appendix S2). The models provided posterior probability distributions of the percent contribution of the four producers to $G$. holbrooki and A. thienemanni somatic composition, and revealed differences in their relative contributions among the three habitats. MixSIAR model comparisons show that $A$. theinemanni and G. holbrooki differ in their diet composition. Although the model comparison does not itself provide insight into what these differences are, Figure 3 shows that although seston is likely to dominate the diets of both species, litter is likely to provide appreciable contributions to $A$. 
theinemanni, while biofilm is the second-most important producer for G. holbrooki. Subsequent model comparisons within consumer species find that the contributions of the producer groups shift among habitats for G. holbrooki, but there is little evidence for such habitat shifts in A. theinemanni (Table 2). Figure 3 indicates that these habitat-specific shifts reflect a slightly larger contribution of biofilm relative to seston for $G$. holbrooki in anabranches than wetlands.

\section{Fatty acids}

Our study showed clear differences in the fatty acid profiles of basal resources available to animals in floodplain wetlands and anabranches compared to the river channel. There was a significant interaction in fatty acid profiles between sources and habitats, with main effects also detected for both factors (Table 1, Figure 4). Pairwise comparisons indicated that fatty acid composition of sources differed between the river channel and wetlands and between wetlands and anabranches, but that fatty acid profiles of sources from river channels and anabranches were similar. Fatty acid profiles of all sources differed from one another (Tables 3 and 4). Overall, a total of 52 individual fatty acids were detected from sources and animals combined (Figure S1, Table S3). Among sources, saturated fatty acids contributed between 29 and $69 \%$ to total fatty acid profiles. Concentrations of all polyunsaturated fatty acids combined were highest in macrophytes (44 - 67\%) and in seston (11 - $25 \%$ ), while mean concentrations of monounsaturated fatty acids among sources were highest in biofilms (29 $\pm 2 \%$, Table 3). Benthic and terrestrial litter profiles were dominated by bacterial fatty acids (Table 3).

Mean percentage contribution of all polyunsaturated fatty acids to total fatty acid profiles of sources were similar among habitats except in seston, where concentration was significantly higher in wetlands (21 $\pm 2 \%)$ than in anabranches $(15 \pm 1 \%)$ or the river channel $(12 \pm 1 \%)$. When the proportion of essential fatty acids within seston were examined separately, values for ALA (18:3 13$)$,

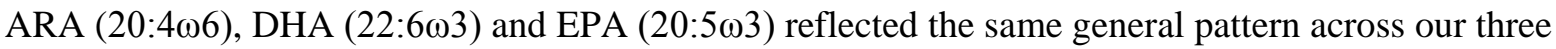


habitat types and were highest in wetlands, intermediate in anabranches and lowest in the river channel (Figure 5). Mean percentage of ALA in seston ranged from $3 \pm 0 \%$ in the river channel to 6 $\pm 1 \%$ in wetlands and, although ARA varied substantially among habitats, mean values ranged from $0.2 \pm 0 \%$ in the river channel, $1 \pm 1 \%$ in anabranches and $2 \pm 1 \%$ in wetlands. Docosahexaenoic acid was not detected in river channel seston but accounted for $0.3 \pm 0 \%$ of fatty acids in anabranches and $1 \pm 0 \%$ in wetlands. Mean percentage contribution of EPA to total fatty acids in seston mirrored patterns displayed by other essential polyunsaturated fatty acids, ranging from $0.5 \pm 0 \%$ in the river channel, $1 \pm 0 \%$ in anabranches and $2 \pm 1 \%$ in wetlands (Figure 5). Mean concentration of bacterial fatty acids was also higher in wetland (9 $\pm 3 \%)$ and anabranch $(11 \pm 3 \%)$ seston than in the river channel $(6 \pm 0 \%)$.

Despite differences in fatty acid profiles of sources among habitats, overall fatty acid profiles of animals were similar among habitats, but differed strongly between identities (Table 1). The mean proportion of monounsaturated fatty acids was higher in A. thienemanni and G. holbrooki (37 \pm 2 and $26 \pm 2 \%$, respectively) than in planktonic and benthic zooplankton (12 $\pm 0.3 \%$ in each). Mean concentrations of polyunsaturated fatty acids in animals showed fairly similar patterns (26 \pm 2 and 29 $\pm 2 \%$, respectively for $A$. thienemanni and G. holbrooki and $11 \pm 1$ and $13 \pm 1 \%$, respectively for planktonic and benthic zooplankton). In contrast to other animals, zooplankton contained higher mean proportions of saturated fatty acids (64 \pm 1 for planktonic and $62 \pm 1 \%$ for benthic, respectively) and bacterial fatty acids (15 \pm 1 for planktonic and $14 \pm 1 \%$ for benthic zooplankton, respectively; Table $3)$.

Bacterial hydroxy fatty acids that contributed to the bacterial fatty acid grouping were primarily detected from terrestrial and benthic litter sources. Of the bacterial fatty acids, 10:0 2-OH contributed $8 \%$ and $9 \%$ to within-source similarity of benthic and terrestrial litter fatty acid profiles, respectively, which then also contributed strongly to within-consumer similarity of planktonic (11\%) 
and benthic zooplankton (10 \%) profiles (Table 4). The bacterial fatty acid 10:0 2-OH was not detected from A. thienemanni samples but was identified in low concentrations in G. holbrooki tissue. Percentage contribution to total fatty acid profiles of the essential fatty acid EPA (20:5 consistently higher in A. thienemanni relative to other animals across all habitat types, with mean values ranging from $5 \pm 1 \%$ in the river channel to $4 \pm 1 \%$ in anabranches (Figure 6 ). In contrast, DHA (22:6 03$)$ was significantly higher $(t=7.11, P<0.001)$ in $G$. holbrooki, with mean proportions

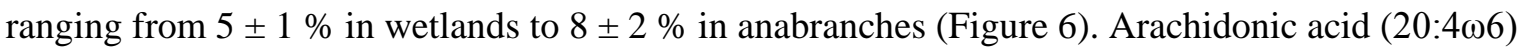
was not detected in zooplankton sampled from the river channel or from anabranches but was recorded in very low concentration ( $0.4 \%$ of total fatty acids) in planktonic zooplankton from one wetland. Mean ALA (18:3@3) concentration was highest in benthic zooplankton (6 $\pm 1 \%)$ across

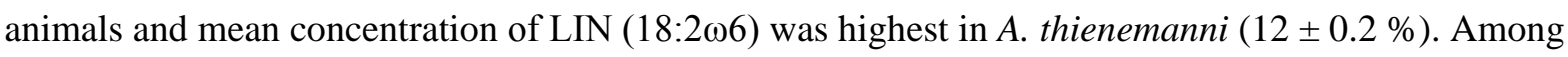
animals the ratio of omega-3 to omega- 6 fatty acids $(\omega 3: \omega 6)$ was highest in benthic zooplankton $(3.80$ $\pm 0.56)$ and lowest in A. thienemanni $(0.62 \pm 0.04)$. The ratio of DHA to EPA was highest in $G$. holbrooki (5.19 \pm 0.66$)$ and lowest in A. thienemanni $(0.04 \pm 0.01)$ and similar between benthic $(0.72$ $\pm 0.21)$ and planktonic zooplankton $(0.54 \pm 0.12$, Table 3$)$.

\section{Discussion}

We predicted that planktonic organic matter in the water column (seston) would be a primary basal resource for animals. Our Bayesian mixing models using a combination of stable isotopes $\delta^{13} \mathrm{C}$ and $\delta^{15} \mathrm{~N}$ and fatty acid biomarkers showed that seston was the dominant carbon source for both of our top consumer species in all three of our habitats. We also revealed clear differences in the fatty acid profiles of basal resources available to animals in floodplain wetlands and anabranches compared to the river channel. Wetland seston contained a higher proportion of polyunsaturated essential fatty acids for zooplankton, a pattern also observed in other systems (Smyntek et al. 2008), that are 
important for development and somatic growth of animals (Guo et al. 2018). In particular, EPA

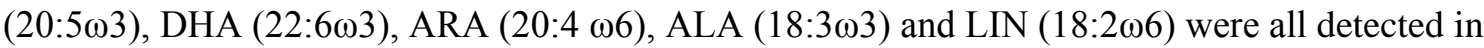
higher concentrations in wetland and anabranch seston, compared with that in the river channel, likely due to algae such as diatoms and cryptophytes (evidenced by higher chlorophyll- $a$ concentrations in these habitats), which are sources of long-chain polyunsaturated fatty acids(Taipale et al. 2011).

In addition to differences in fatty acids, $\delta^{13} \mathrm{C}$ values were also lowest in anabranch and wetland seston. Low seston $\delta^{13} \mathrm{C}$ values suggest potential assimilation of dissolved inorganic carbon derived from soil-respired $\mathrm{CO}_{2}$ in groundwater (Burrows et al. 2018), which is consistent with the recognised importance of alluvial groundwater to wetlands along the Oven's river during periods of hydraulic disconnection (Yu et al. 2013). Another possible explanation for low $\delta^{13} \mathrm{C}$ values in anabranch and wetland habitats is methanotrophic bacterial activity, however we believe this explanation is unlikely for three reasons: (1) none of our animals were highly $\delta^{13} \mathrm{C}$ isotopically lighter (e.g. < - 40 , Kohzu et

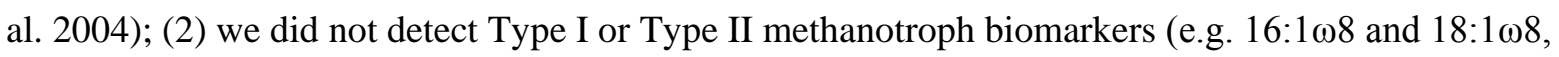
Bowman et al. 1991); and (3) the Ovens River floodplain anabranches and wetlands can be sustained by groundwater during periods of disconnection from the river (Yu et al. 2013).

Isotopic values of animals were within the ranges of values reported for the Ovens River (Hladyz et al. 2012) and elsewhere (Rees et al. 2020), although our $\delta^{13} \mathrm{C}$ values were generally lower (e.g. -35.11 $\pm 0.67 \%$ SE compared to $-30 \%$, Hladyz et al. 2012). Low consumer $\delta^{13} \mathrm{C}$ values may be due to differences in taxonomic resolution (i.e. species versus genus) or because we sampled during low flows, when groundwater contributions to the river channel are relatively higher. Of our two higher animals, A. thienemanni collected from wetland habitats displayed the highest reliance on seston based on stable isotope analyses, supporting previous work on the Ovens River in which seston contributed most to invertebrate consumer biomass (Hladyz et al. 2012). Isotopic patterns among biofilms mirrored those of seston, with the lowest mean $\delta^{13} \mathrm{C}$ values observed in anabranch and 
wetland habitats. Biofilms were predominantly sampled from leaf litter, and are likely dominated by bacteria (given the higher proportions of monounsaturated fatty acids and bacterial fatty acids than for seston). Isotopic values of macrophytes varied substantially, likely reflecting the range of taxa, combinations of carbon fixation mechanisms (e.g. C3 or C4), and differences in growth habits.

Although the concentration of essential fatty acids in river seston was lower than in floodplain seston, animals collected in the river channel had similar concentrations of essential fatty acids to those collected in wetlands and anabranches. In Australian temperate floodplain ecosystems, wetland habitats can support higher densities of zooplankton than the river channel ( $3000-6000$ compared to $<2500$ animals/L; Ning et al. 2013; Tan and Shiel 1993) - a pattern that was also evident within our study habitats at the time of sampling (e.g. mean benthic and pelagic zooplankton density was significantly higher in anabranches and wetlands than in the river channel, Price et al. 2019). Though outside the scope of this study, we think it possible that higher concentrations of high-quality longchain polyunsaturated fatty acids in wetland seston could be partly responsible (along with other habitat variables such as temperature and flow) for supporting higher densities of zooplankton within anabranches and wetlands, and that lower concentrations of essential fatty acids could result in zooplankton population limitation within the river channel (e.g. Müller-Navarra 1995). Future work should focus on determining if comparatively lower concentrations of essential fatty acids in the river channel are in fact limiting to animals by evaluating mass fractions of essential fatty acids between trophic levels.

Eicosapentaenoic acid and DHA are important for neural development and vision, along with cellular membrane functioning (Parrish 2009) and in our study we saw clear differences in their proportions among different habitats and animals. Fatty acid profiles of anabranch and wetland G. holbrooki were high in DHA compared to basal resources and other animals, comparable with other studies of freshwater ecosystems (Guo et al. 2017), suggesting that G. holbrooki synthesise DHA from dietary 
precursors or preferentially retain DHA. Docosahexaenoic acid comprised c. $6.5 \%$ of total fatty acids for G. holbrooki (Cyprinodontiformes), appreciably less than values reported for Salmoniformes and Perciformes (c. $24 \%$ of total fatty acids), but similar to those for Cypriniformes and Siluriformes (c. 5\% of total fatty acids; Guo et al. (2017). Gambusia holbrooki is a generalist carnivore that feeds principally on zooplankton, both at the surface and within the water column. These behaviors were reflected in our study in which G. holbrooki tissue primarily incorporated seston and to a lesser degree biofilm, both of which are important food resources for zooplankton (Ning et al. 2013). Previous work on the Ovens River established that terrestrial litter contributed comparatively more to fish tissue than we estimated in the present study (Hladyz et al. 2012), and supplementation of consumer diets with terrestrial inputs may make clear discrimination of food sources difficult.

Anisops thienemanni contained a high proportion of EPA ( $\sim 4.5 \%$ of total fatty acids) relative to other animals, also consistent with other studies of Anisops spp., (e.g. 10-12\%, Ghioni et al. 1996). Eicosapentaenoic acid is preferentially retained by invertebrates generally, and is essential for development, reproduction and hormone regulation for many invertebrates (Guo et al. 2017). In contrast with findings for other genera belonging to the family Notonectidae (e.g. Sushchik et al. 2016), we found no significant differences in fatty acid profiles of $A$. thienemanni between habitats. Linoleic acid was also higher within A. thienemanni than other animals ( 12 \% c.f. $\sim 6 \%$ for $G$. holbrooki and $<2 \%$ for zooplankton) and double previously reported proportions for Notonectidae (Ghioni et al. 1996). Linoleic acid is a precursor of ARA and is only produced by algae and plants (Sargent et al. 1995). Given the low concentration of LIN within the primary food source of $A$. thienemani (i.e. zooplankton, Ho et al. 2011), LIN is likely highly retained within A. thienemani. Similarly, zooplankton contained higher concentrations of EPA and DHA than their primary food source, seston. Elevated EPA and DHA concentration among zooplankton suggests that they selectively assimilate the most physiologically-important fatty acids by preferential incorporation and 


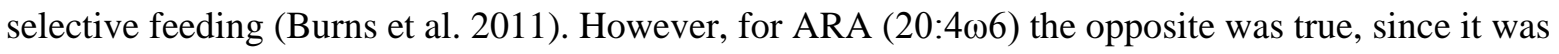
present within all basal resources except terrestrial litter, but not detected (or in very low concentrations) in benthic and planktonic zooplankton. Arachidonic acid is a precursor for biologically active eicosanoids that are critical compounds of cell membranes and plays many important roles in facilitating and controlling cellular activities (Parrish 2009). Our findings are unusual, since ARA is the most efficiently retained polyunsaturated fatty acid in planktonic organisms of oligotrophic lakes (Kainz et al. 2004) and may be a limiting factor for fish recruitment success, as it is essential for early development of marine fish (Izquierdo et al. 2000).

Zooplankton, such as Cladocera, can selectively target high-quality phytoplankton for food when available (e.g. Galloway et al. 2014). However, in our study, zooplankton fatty acid profiles from all habitats were consistent with concentrations observed in litter and, to a lesser degree, biofilm, suggesting that heterotrophic energy pathways were important. The bacterial fatty acid 10:0 2-OH was traced from benthic litter, to benthic and planktonic zooplankton and detected in lower concentrations within G. holbrooki. This compound is a hydroxylated fatty acid commonly associated with freshwater bacteria (Santos et al. 2018), but has not previously been widely used as a food web biomarker. These results are also supported by the ratio of $\omega 3: \omega 6$ fatty acids among animals, which were highest in benthic zooplankton and have previously been used as an indicator of heterotrophy in planktonic food webs (Jardine et al. 2015). Within all three of our habitats biofilms were predominantly collected of the surfaces of E. camaldulensis leaves (the dominant surface for most locations), and as such, the biofilm matrix was likely characterized by high a proportion of bacteria, perhaps explaining the elevated proportion of bacterial fatty acids among zooplankton animals.

The importance of floodplain inundation for riverine productivity (e.g. Humphries et al. 2014) is a central paradigm of freshwater ecology. We identify a mechanism by which that relationship may exist - river-floodplain connectivity could provide higher quality food resources for animals than are 
available in the river channel (e.g. Figure 7). Our results suggest that while inundation of floodplains is a highly important first step in river management, subsequent reconnection to the river may be important to: 1/ mobilize high quality food resources to the main channel; and 2/ to afford riverine animals the opportunity to access high quality resources by moving onto the floodplain. Although it is important to acknowledge the limits of inference from this short-term study, seston was a principal food resource for animals and we observed clear differences in the quality of seston from the river channel and floodplain habitats after a 4-week disconnection, however, further research is required to understand both the optimum connection/disconnection dynamics, along with optimum flooding duration. Season is also likely to be an important factor when planning environmental flows to maximize food quality, as microbial activity can be temperature and light sensitive. Timing may also be important when taxa have seasonal needs for high-quality food to ensure breeding success (e.g. abundant high-quality food is needed in spring and autumn to support recruitment for temperate Australian fish.

\section{Conclusions}

Our research shows the importance of determining the quality of organic matter for incorporation into food webs, and the potential role of targeted environmental flows to re-establish critical energy pathways in riverine ecosystems. There is strong evidence of the role of floodplains in generating high-quality food resources critical to animal growth. However we believe that significant knowledge gaps in our understanding of floodplain-river interactions persist, and that more work is required to determine if the low concentrations of essential fatty acids that we observed in the river channel are in fact limiting to animals. Resource limitation needs to be assessed by evaluating the transfer of mass fractions of essential fatty acids between trophic levels. Given the emerging use of infrastructure to reconnect river and floodplain habitats by pumping water from the river channel rather than relying on natural overbank floods, there is a pressing need for river managers to better understand the hydraulic 
requirements to ensure that there is flux of these essential materials from floodplains into riverine ecosystems.

\section{Acknowledgements}

This research was funded by the Australian Commonwealth Department of Environment and Energy under the Environmental Watering Knowledge and Research program. We thank John Pengelly from the Commonwealth Scientific and Industrial Research Organization for dissolved organic carbon and Chlorophyll $-a$ analyses. We thank Douglas Ford from University of Western Australia for stable isotope analyses and David Francis from Deakin University is thanked for analyses of fatty acids. We thank Michael Shackleton of La Trobe University for production of Figure 1. We also thank three anonymous reviewers and the editor Bob Hall whose insightful comments improved our manuscript.

\section{Conflict of Interest}

None declared.

\section{References}

Anderson, M. 2005. Permanova: A FORTRAN computer program for permutational multivariate analysis of variance. Department of Statistics.

Anderson, M., R. N. Gorley, and R. K. Clarke. 2008. Permanova+ for Primer: Guide to Software and Statistical Methods. PRIMER-E, Plymouth, UK.

Beesley, L. and others 2012. Does flooding affect spatiotemporal variation of fish assemblages in temperate floodplain wetlands? Freshwater Biol 57: 2230-2246.

This article is protected by copyright. All rights reserved. 
Bowman, J. P., J. H. Skerratt, P. D. Nichols, and L. I. Sly. 1991. Phospholipid fatty acid and lipopolysaccharide fatty acid signature lipids in methane-utilizing bacteria. FEMS Microbiol. Lett. 85: 15-22.

Brett, M. T., D. C. Müller-Navarra, and J. Persson. 2009. Crustacean zooplankton fatty acid composition, p. 115-146. In M. Kainz, M. Brett and M. Arts [eds.], Lipids in aquatic ecosystems. Springer.

Brisbane Declaration. 2007. Environmental flows are essential for freshwater ecosystem health and human well-being. 10th International River Symposium and International Environmental Flows Conference, 3-6 September 2007, Brisbane, Australia. Retrieved from https://www.conservationgateway.org/Files/Pages/brisbane-declaration.aspx.

Burns, C. W., M. T. Brett, and M. Schallenberg. 2011. A comparison of the trophic transfer of fatty acids in freshwater plankton by cladocerans and calanoid copepods. Freshwater Biol 56: 889903.

Burrows, R. M. and others 2018. Groundwater supports intermittent-stream food webs. Freshw Sci 37: 42-53.

Christie, W. 2003. Lipid Analysis: Isolation, Separation, Identification and Structural Analysis of Lipids, 3 ed. The Oily Press.

Clarke, K. R. 1993. Non-parametric multivariate analyses of changes in community structure. Aust J Ecol 18: 117-117.

Conlan, J. A., M. M. Rocker, and D. S. Francis. 2017. A comparison of two common sample preparation techniques for lipid and fatty acid analysis in three different coral morphotypes reveals quantitative and qualitative differences. PeerJ 5: e3645.

Dwyer, G. K., R. J. Stoffels, G. N. Rees, M. E. Shackleton, and E. Silvester. 2018. A predicted change in the amino acid landscapes available to freshwater carnivores. Freshw Sci 37: 108-120.

This article is protected by copyright. All rights reserved. 
Galloway, A. W. and others 2014. Diet-specific biomarkers show that high- quality phytoplankton fuels herbivorous zooplankton in large boreal lakes. Freshwater Biol 59: 1902-1915.

Ghioni, C., J. Bell, and J. Sargent. 1996. Polyunsaturated fatty acids in neutral lipids and phospholipids of some freshwater insects. Comparative Biochemistry and Physiology Part B: Biochemistry and Molecular Biology 114: 161-170.

Giling, D., P. Reich, and R. M. Thompson. 2009. Loss of riparian vegetation alters the ecosystem role of a freshwater crayfish (Cherax destructor) in an Australian intermittent lowland stream. J North Am Benthol Soc 28: 626-637.

Growns, I. and others 2020. The use of fatty acids to identify food sources of secondary consumers in wetland mesocosms. J Freshw Ecol 35: 173-189.

Guo, F. and others 2018. Feeding strategies for the acquisition of high-quality food sources in stream macroinvertebrates: Collecting, integrating, and mixed feeding. Limnol Oceanogr 63: 19641978.

Guo, F., S. E. Bunn, M. T. Brett, and M. J. Kainz. 2017. Polyunsaturated fatty acids in stream food webs-high dissimilarity among producers and consumers. Freshwater Biol 62: 1325-1334.

Gutreuter, S., A. D. Bartels, K. Irons, and M. B. Sandheinrich. 1999. Evaluation of the flood-pulse concept based on statistical models of growth of selected fishes of the Upper Mississippi River system. Can J Fish Aquat Sci 56: 2282-2291.

Happel, A., L. Stratton, C. Kolb, C. Hays, J. Rinchard, and S. Czesny. 2016. Evaluating quantitative fatty acid signature analysis (QFASA) in fish using controlled feeding experiments. Can J Fish Aquat Sci 73: 1222-1229.

Hladyz, S., D. L. Nielsen, P. J. Suter, and E. S. Krull. 2012. Temporal variations in organic carbon utilization by consumers in a lowland river. River Res Appl 28: 513-528.

This article is protected by copyright. All rights reserved. 
Ho, S. S., N. R. Bond, and P. S. Lake. 2011. Comparing food-web impacts of a native invertebrate and an invasive fish as predators in small floodplain wetlands. Mar Freshw Res 62: 372-382.

Holland, A., P. J. McInerney, M. E. Shackleton, G. N. Rees, N. R. Bond, and E. Silvester. 2020. Dissolved organic matter and metabolic dynamics in dryland lowland rivers. Spectrochim Acta A Mol Biomol Spectrosc 229: 117871.

Humphries, P., H. Keckeis, and B. Finlayson. 2014. The river wave concept: integrating river ecosystem models. Bioscience 64: 870-882.

Izquierdo, M., J. Socorro, L. Arantzamendi, and C. Hernández-Cruz. 2000. Recent advances in lipid nutrition in fish larvae. Fish Physiol Biochem 22: 97-107.

Jardine, T. D. and others 2015. Reconciling the role of organic matter pathways in aquatic food webs by measuring multiple tracers in individuals. Ecology 96: 3257-3269.

Kainz, M., M. T. Arts, and A. Mazumder. 2004. Essential fatty acids in the planktonic food web and their ecological role for higher trophic levels. Limnol Oceanogr 49: 1784-1793.

Kohzu, A. and others 2004. Stream food web fueled by methane-derived carbon. Aquat Microb Ecol 36: $189-194$.

McCutchan Jr, J. H., W. M. Lewis Jr, C. Kendall, and C. C. McGrath. 2003. Variation in trophic shift for stable isotope ratios of carbon, nitrogen, and sulfur. 102: 378-390.

McInerney, P. J., R. J. Stoffels, M. E. Shackleton, and C. D. Davey. 2017. Flooding drives a macroinvertebrate biomass boom in ephemeral floodplain wetlands. Freshw Sci 36: 726-738.

Müller-Navarra, D. 1995. Evidence that a highly unsaturated fatty acid limits Daphnia growth in nature. Archiv für Hydrobiologie 132: 297-307.

Ning, N. S. P., B. Gawne, R. A. Cook, and D. L. Nielsen. 2013. Zooplankton dynamics in response to the transition from drought to flooding in four Murray-Darling Basin rivers affected by differing levels of flow regulation. Hydrobiologia 702: 45-62.

This article is protected by copyright. All rights reserved. 
O'Donovan, S. A., S. M. Budge, K. A. Hobson, A. P. Kelly, and A. E. Derocher. 2018.

Intrapopulation variability in wolf diet revealed using a combined stable isotope and fatty acid approach. Ecosphere 9: e02420.

Oboh, A. and others 2017. Two alternative pathways for docosahexaenoic acid (DHA, 22:6n-3) biosynthesis are widespread among teleost fish. Scientific Reports 7: 3889.

Parrish, C. C. 2009. Essential fatty acids in aquatic food webs, p. 309-326. In M. T. Arts, M. T. Brett and M. J. Kainz [eds.], Lipids in aquatic ecosystems. Springer.

Price, A., S. Balcombe, P. Humphries, A. King, and B. Zampatti. 2019. Murray-Darling Basin Environmental Water Knowledge and Research Project — Fish Theme Research Report, p. 50. Report prepared for the Department of the Environment and Energy, Commonwealth Environmental Water Office by La Trobe University, Centre for Freshwater Ecosystems (formerly Murray-Darling Freshwater Research Centre), CFE Publication 223.

Rees, G. N., R. A. Cook, N. S. P. Ning, P. J. McInerney, R. T. Petrie, and D. L. Nielsen. 2020. Managed floodplain inundation maintains ecological function in lowland rivers. Sci Total Environ 727: 138469.

Santos, I. C., J. Smuts, W.-S. Choi, Y. Kim, S. B. Kim, and K. A. Schug. 2018. Analysis of bacterial FAMEs using gas chromatography - vacuum ultraviolet spectroscopy for the identification and discrimination of bacteria. Talanta 182: 536-543.

Sargent, J., G. Bell, L. McEvoy, D. Tocher, and A. Estevez. 1999. Recent developments in the essential fatty acid nutrition of fish. Aquaculture 177: 191-199.

Sargent, J., J. Bell, M. Bell, R. Henderson, and D. Tocher. 1995. Requirement criteria for essential fatty acids. J Appl Ichthyol 11: 183-198.

This article is protected by copyright. All rights reserved. 
Smyntek, P. M., M. A. Teece, K. L. Schulz, and A. J. Storch. 2008. Taxonomic differences in the essential fatty acid composition of groups of freshwater zooplankton relate to reproductive demands and generation time. Freshwater Biol 53: 1768-1782.

Stock, B. C., A. L. Jackson, E. J. Ward, A. C. Parnell, D. L. Phillips, and B. X. Semmens. 2018. Analyzing mixing systems using a new generation of Bayesian tracer mixing models. PeerJ 6: e5096.

Stock, B. C., and B. X. Semmens. 2016a. MixSIAR GUI user manual, version 1.0. Accessible online at: http://conserver. iugo-cafe. org/user/brice. semmens/MixSIAR.

Stock, B. C., and B. X. Semmens. 2016b. Unifying error structures in commonly used biotracer mixing models. Ecology 97: 2562-2569.

Sushchik, N. N., Y. A. Yurchenko, O. E. Belevich, G. S. Kalachova, A. A. Kolmakova, and M. I. Gladyshev. 2016. Waterbugs (Heteroptera: Nepomorpha and Gerromorpha) as sources of essential n-3 polyunsaturated fatty acids in Central Siberian ecoregions. Freshwater Biol 61: $1787-1801$.

Taipale, S. J., M. J. Kainz, and M. T. Brett. 2011. Diet-switching experiments show rapid accumulation and preferential retention of highly unsaturated fatty acids in Daphnia. Oikos 120: $1674-1682$.

Tan, L.-W., and R. J. Shiel. 1993. Responses of billabong rotifer communities to inundation. Hydrobiologia 255: 361-369.

Twining, C. W., J. T. Brenna, N. G. Hairston Jr, and A. S. Flecker. 2016. Highly unsaturated fatty acids in nature: what we know and what we need to learn. Oikos 125: 749-760.

Warton, D. I., and F. K. C. Hui. 2011. The arcsine is asinine: the analysis of proportions in ecology. Ecology 92: 3-10. 
Yu, M., I. Cartwright, J. Braden, and S. De Bree. 2013. Examining the spatial and temporal variation of groundwater inflows to a valley-to-floodplain river using $222 \mathrm{Rn}$, geochemistry and river discharge: the Ovens River, southeast Australia. Hydrology and Earth System Sciences 17: 4907-4924.

This article is protected by copyright. All rights reserved. 


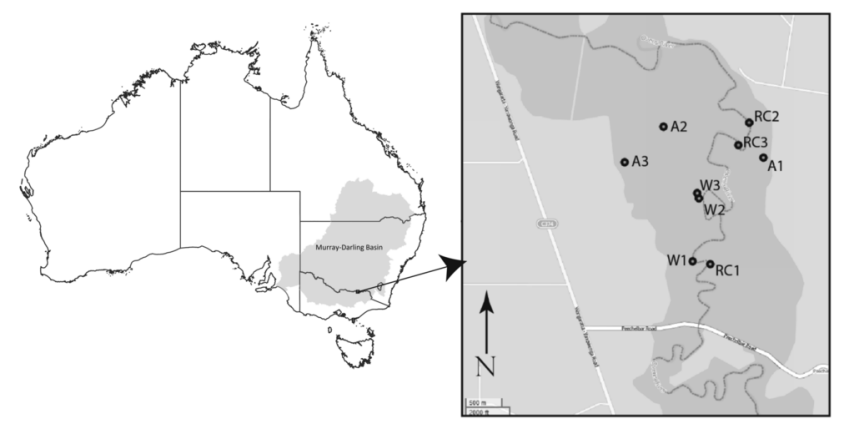

LNO_11548_Fig. 1 bw.tif

This article is protected by copyright. All rights reserved. 


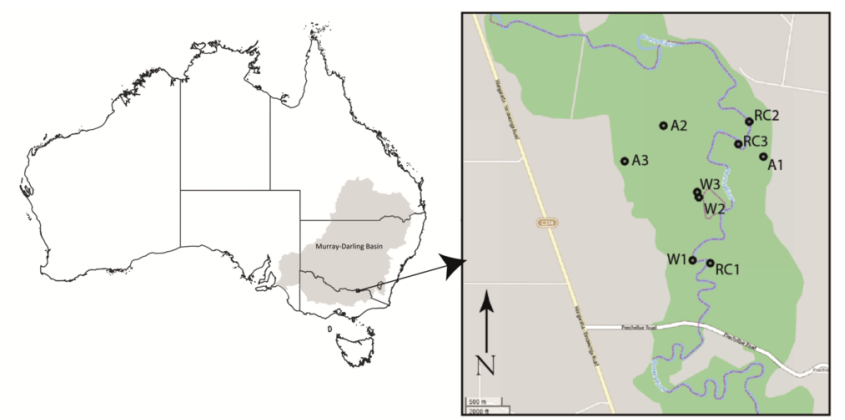

LNO_11548_Fig. 1.tif

This article is protected by copyright. All rights reserved. 


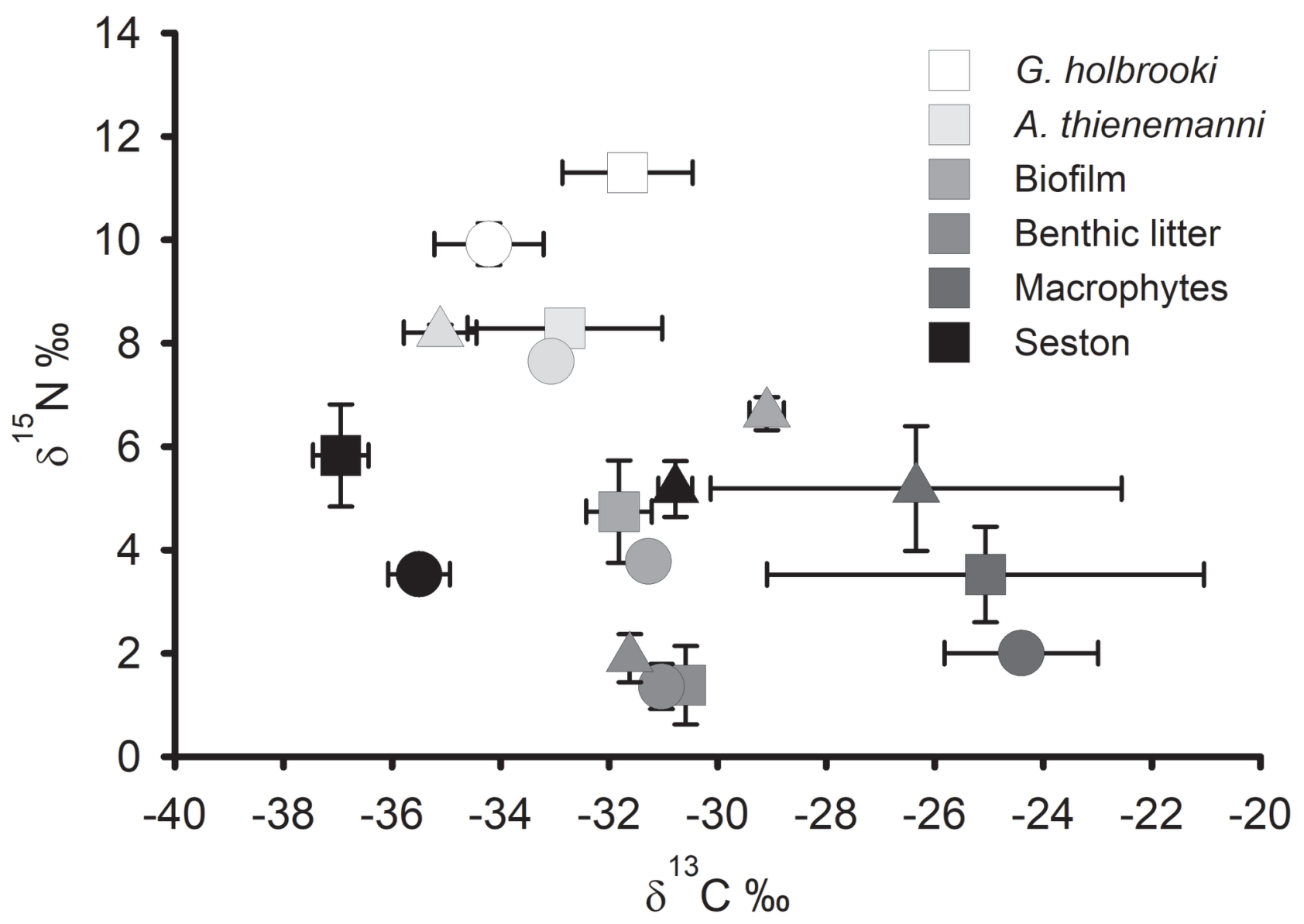

LNO_11548_Fig. 2 bw.TIF 


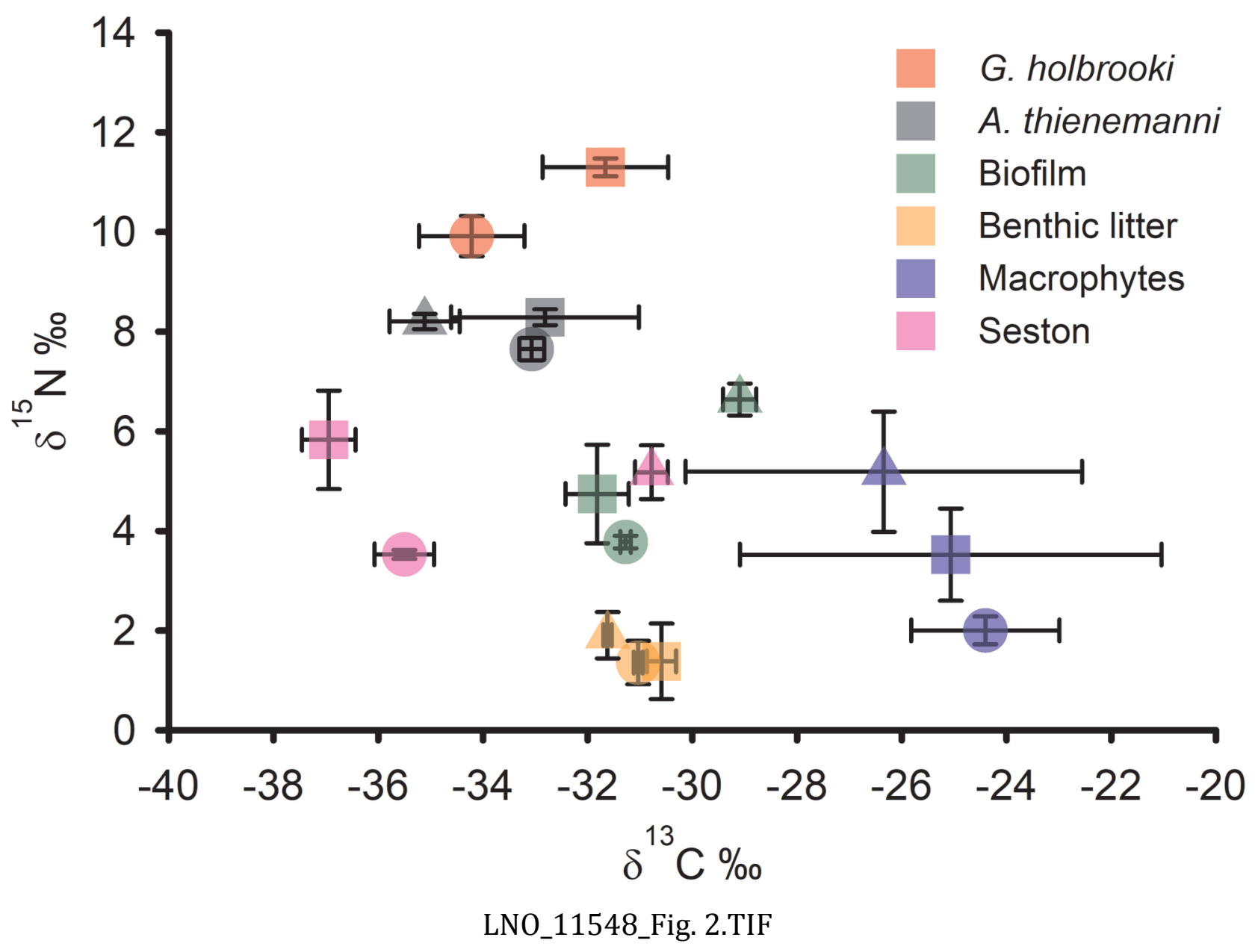

This article is protected by copyright. All rights reserved. 


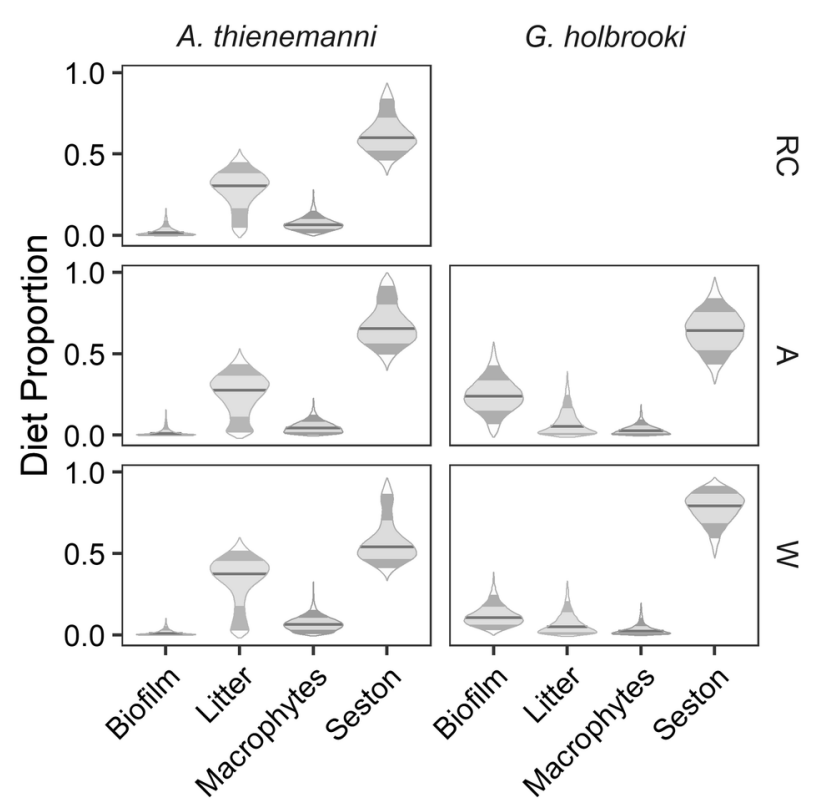

LNO_11548_Fig. 3 bw.tiff

This article is protected by copyright. All rights reserved. 


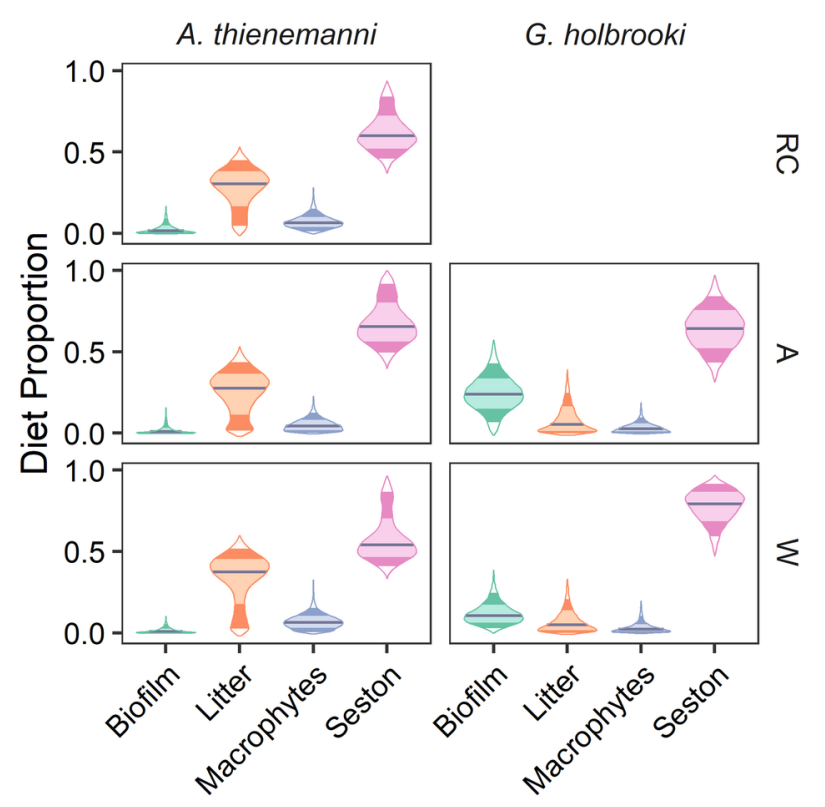

LNO_11548_Fig. 3.tiff

This article is protected by copyright. All rights reserved. 


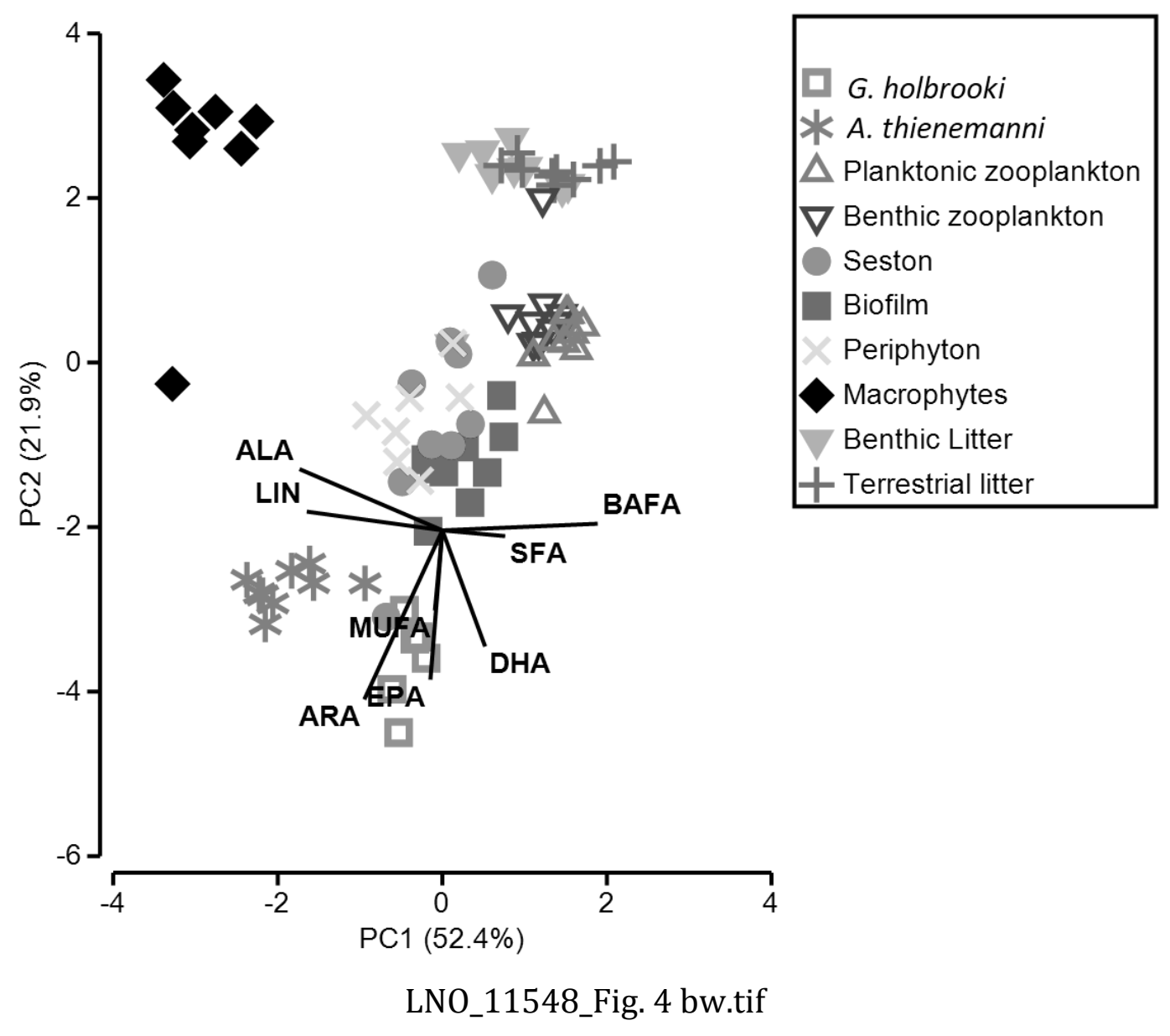

This article is protected by copyright. All rights reserved. 


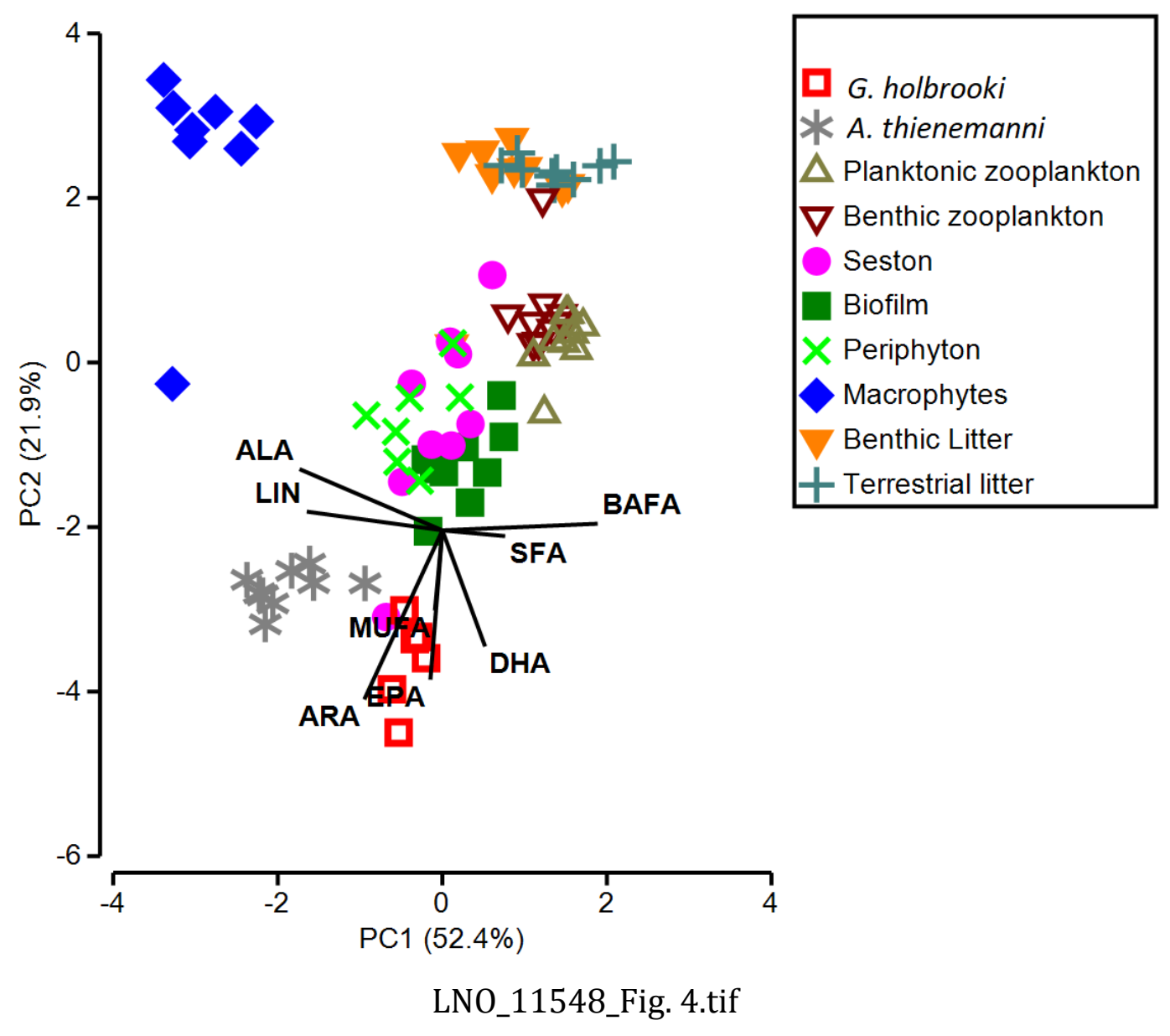

This article is protected by copyright. All rights reserved. 

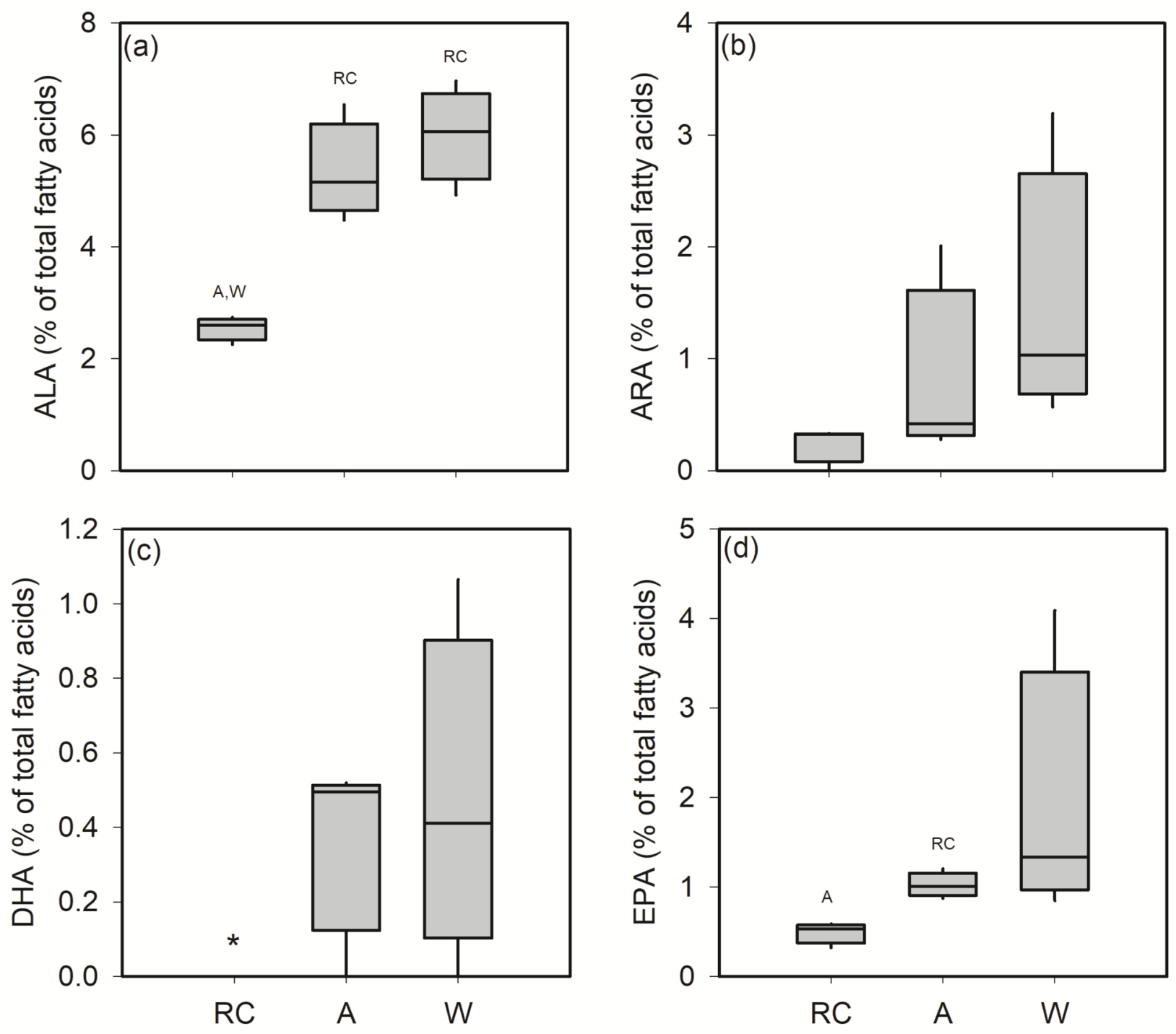

LNO_11548_Fig. 5a.tif 

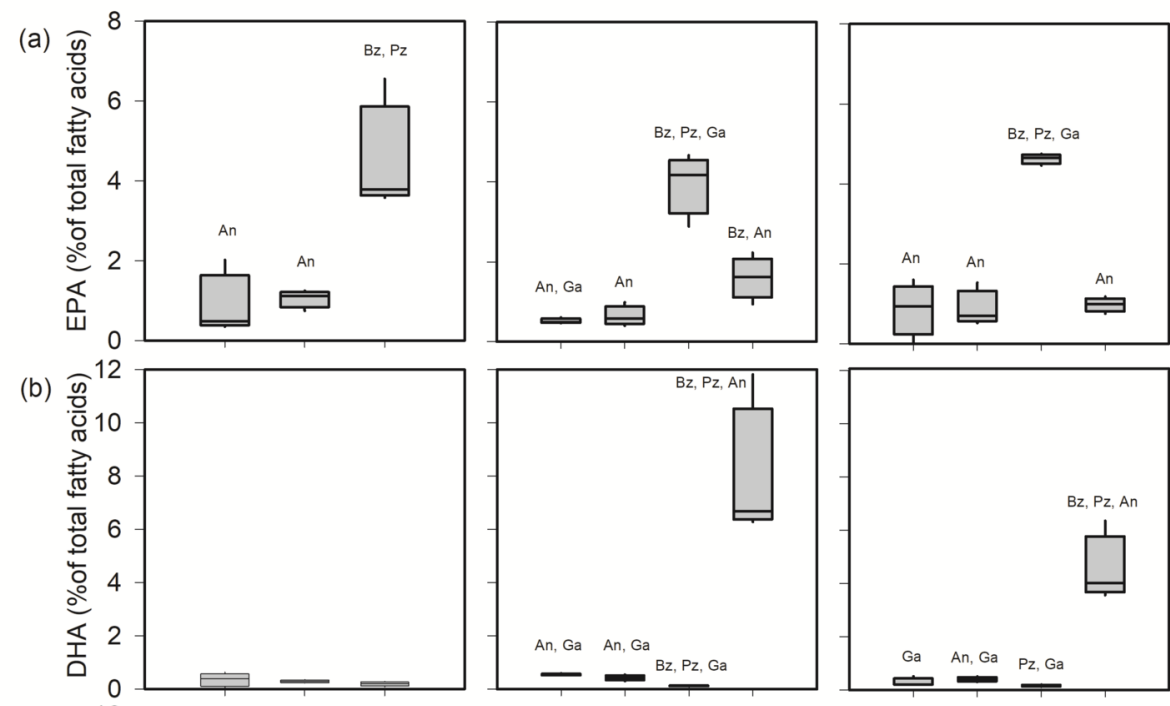

(c)
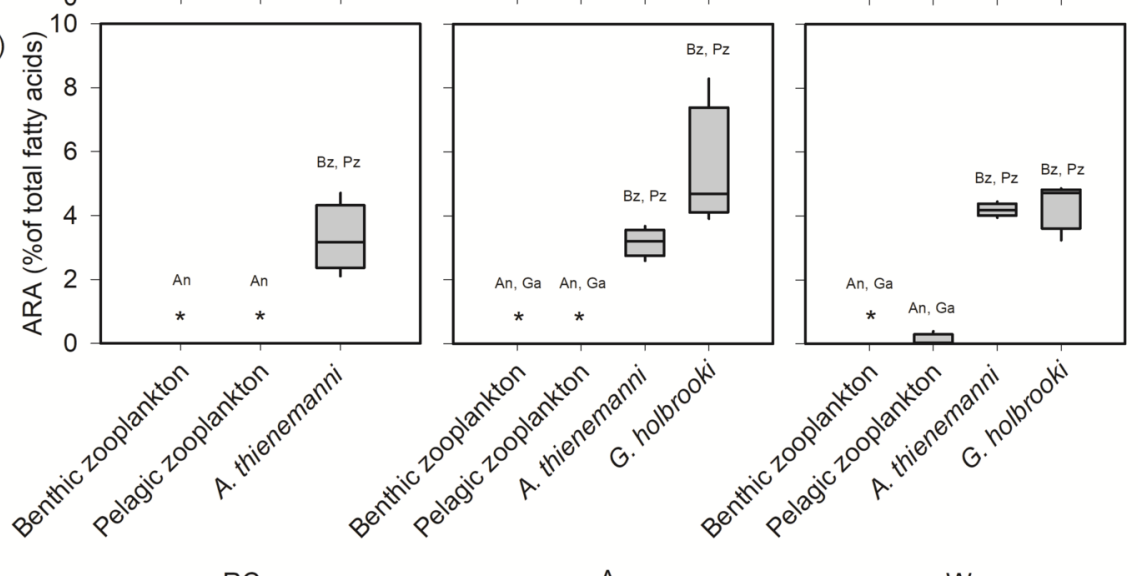

(i)

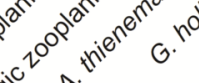

op $+n_{e} e^{e n} e^{n}$

$\mathrm{RC}$

A

w

LNO_11548_Fig. 6a.tif 


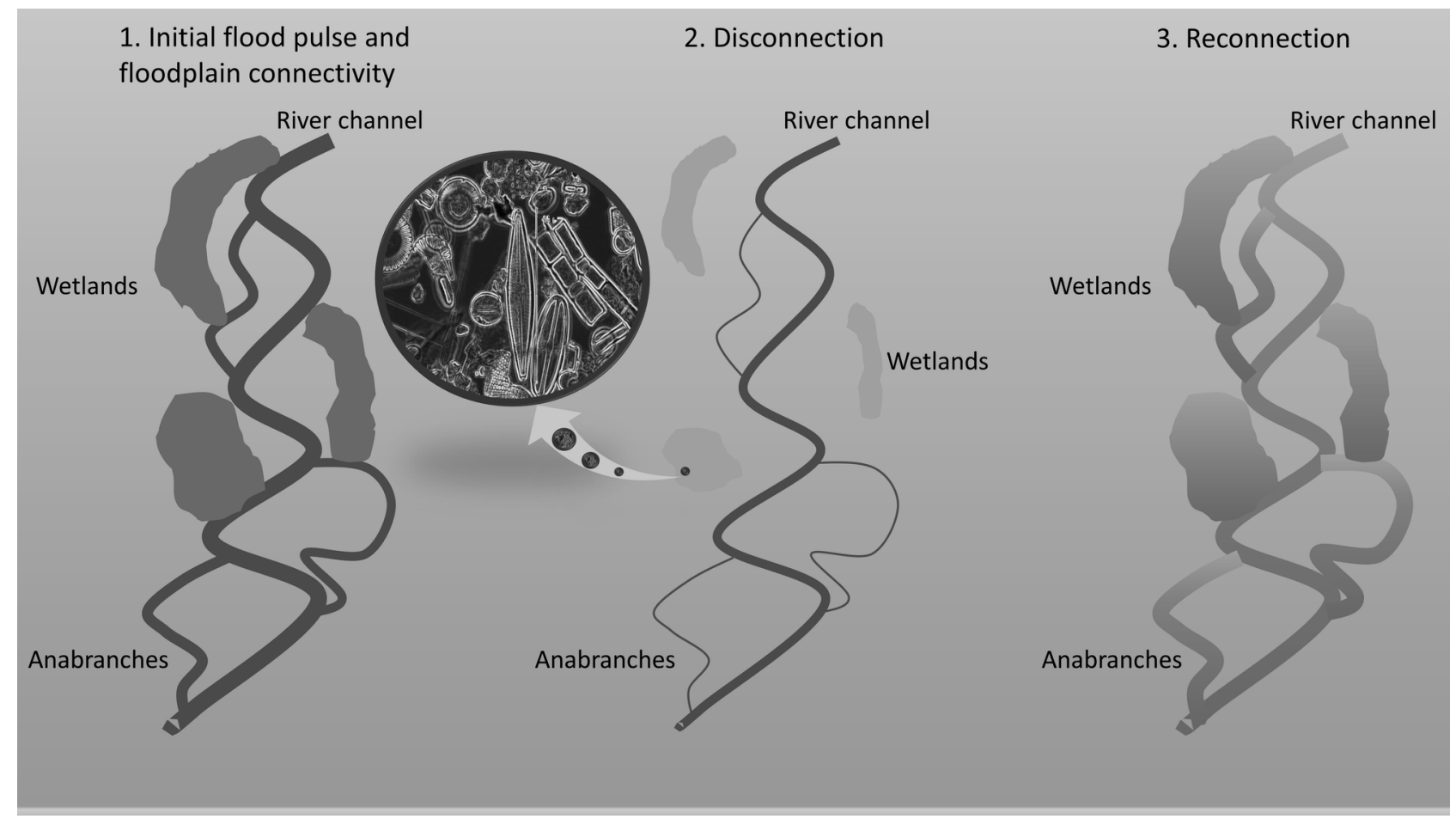

LNO_11548_Fig. 7 bw.tif

This article is protected by copyright. All rights reserved. 


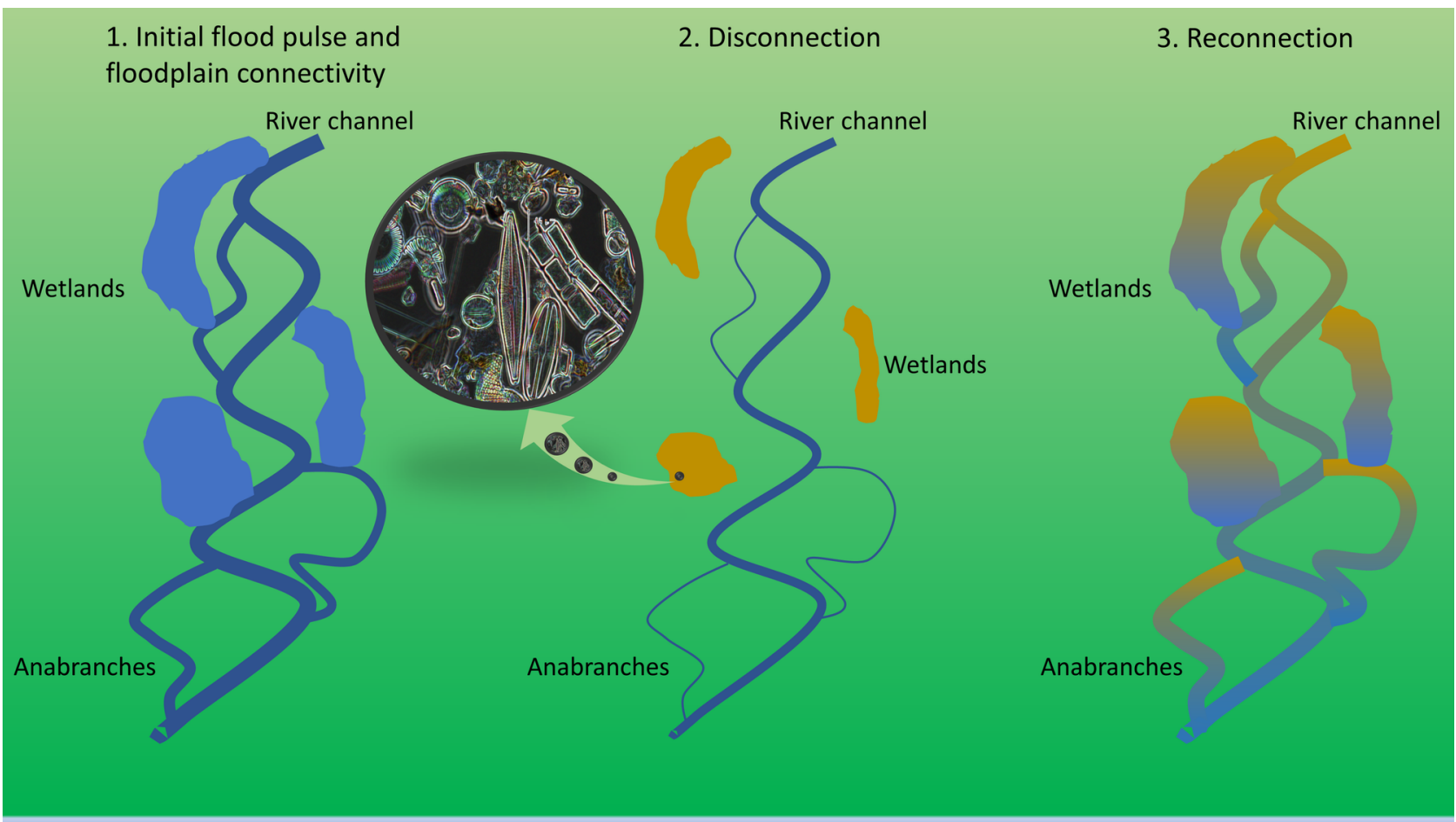

LNO_11548_Fig. 7.tif

This article is protected by copyright. All rights reserved. 
Table 1. Permutational analysis of variance (PERMANOVA) results for $\delta^{13} \mathrm{C}, \delta^{15} \mathrm{~N}$ and fatty acid profiles.

\begin{tabular}{llrrrrrrrr}
\hline \multirow{2}{*}{ Variable } & \multirow{2}{*}{ Factor } & \multicolumn{3}{c}{$\delta^{13} \mathrm{C}$} & \multicolumn{3}{c}{$\delta^{15} \mathrm{~N}$} & \multicolumn{3}{c}{ Fatty acids } \\
\cline { 3 - 10 } & & $\mathrm{df}$ & Pseudo-F & $P$ & Pseudo-F & $P$ & $\mathrm{df}$ & Pseudo-F & $P$ \\
\hline Sources & Habitat & 2,39 & 0.76 & 0.497 & 6.78 & $\mathbf{0 . 0 0 5}$ & 2,50 & 3.30 & $\mathbf{0 . 0 0 4}$ \\
& Identity & 4,39 & 9.79 & $\mathbf{0 . 0 0 1}$ & 9.29 & $\mathbf{0 . 0 0 1}$ & 5,50 & 23.98 & $\mathbf{0 . 0 0 1}$ \\
& Habitat $\times$ Identity & 7,39 & 1.03 & 0.448 & 0.76 & 0.626 & 10,50 & 1.62 & $\mathbf{0 . 0 3 3}$ \\
Animals & Habitat & 2,14 & 1.38 & 0.307 & 5.95 & $\mathbf{0 . 0 2 9}$ & 2,32 & 1.23 & 0.294 \\
& Identity & 1,14 & 0.01 & 0.998 & 78.26 & $\mathbf{0 . 0 0 1}$ & 3,32 & 49.26 & $\mathbf{0 . 0 0 1}$ \\
& Habitat $\times$ Identity & 1,14 & 0.71 & 0.429 & 1.54 & 0.240 & 5,32 & 1.12 & 0.360 \\
\hline
\end{tabular}


Table 2. Comparisons of mixing models using leave one out cross-validation (LOO). LOOic is the leave-one out information criterion, with lower numbers indicating better models. dLOOIC is the difference in LOOic values between each model and the model with lowest LOOic, similar and so is similar to $\triangle \mathrm{AIC}$. The respective se _ are the standard errors of these estimates. The Akaike weights are estimates of the probability that each model will make the best predictions on new data. For the comparisons including both taxa, the model with only species received 95\% of the Akaike weight, and so has a 95\% chance of being the best model. The habitat model for $G$. holbrooki diet (that is, diets differ between habitats) received $90 \%$ of the Akaike weight. In contrast, the best for A. theinemanni received was the null (diets don't differ between habitats, with $91 \%$ of the Akaike weight. Thus, both taxa differ in their diets, and the diet composition of $G$. holbrooki differs between habitats, although this difference is minor, as can be seen in Figure 3 . The $\delta^{13} \mathrm{C}$ and $\delta^{15} \mathrm{~N}$ are the multiplicative error terms $(\xi)$ from MixSIAR for those tracers. See Stock et al. (2018) for further discussion of the interpretation of model comparisons using MixSIAR.

\begin{tabular}{|c|c|c|c|c|c|c|c|}
\hline \multicolumn{8}{|c|}{ Models including both taxa } \\
\hline Model & LOOic & se_LOOic & dLOOic & se_dLOOic & \multicolumn{2}{|c|}{ Akaike weight $\delta^{13} \mathrm{C}$} & $\delta^{15} \mathrm{~N}$ \\
\hline Species & 227.3 & 12.8 & 0 & NA & 0.952 & 1.4 & 0.3 \\
\hline Spp x Habitat & 233.3 & 12.6 & 6 & 2.9 & 0.047 & 1.1 & 0.3 \\
\hline Null & 241.3 & 13.2 & 14 & 6.3 & 0.001 & 0.9 & 0.5 \\
\hline Habitat & 244.3 & 13.1 & 17 & 6.5 & 0 & 0.8 & 0.4 \\
\hline \multicolumn{8}{|c|}{ Within G. holbrooki } \\
\hline Model & LOOic & se_LOOic & dLOOic & se_dLOOic & \multicolumn{2}{|c|}{ Akaike weight $\delta^{13} \mathrm{C}$} & $\delta^{15} \mathrm{~N}$ \\
\hline Habitat & 80.9 & 9.6 & 0 & NA & 0.9 & 2.2 & 0.9 \\
\hline Null & 85.3 & 10.8 & 4.4 & 2.2 & 0.1 & 1.9 & 1 \\
\hline \multicolumn{8}{|c|}{ Within A. theinemanni } \\
\hline Model & LOOic & se_LOOic & dLOOic & se_dLOOic & \multicolumn{2}{|c|}{ Akaike weight $\delta^{13} \mathrm{C}$} & $\delta^{15} \mathrm{~N}$ \\
\hline Null & 138.7 & 9.5 & 0 & $\mathrm{NA}$ & 0.913 & 2.5 & 0.1 \\
\hline Habitat & 143.4 & 8 & 4.7 & 2.4 & 0.087 & 2 & 0.1 \\
\hline
\end{tabular}


Table 3: Contribution (\%) to source and animal profiles for all habitats combined of fatty acid classes saturated (SFA), monounsaturated (MUFA) and polyunsaturated fatty acids (PUFA); essential fatty acids eicosapentaenoic (EPA), docosahexaenoic (DHA), arachidonic (ARA), alpha-linolenic (ALA) and linoleic acid (LIN); $\omega 3: \omega 6$ and DHA:EPA ratios.

\begin{tabular}{|c|c|c|c|c|c|c|c|c|c|c|c|c|c|c|c|c|c|c|c|c|c|c|}
\hline & \multicolumn{2}{|c|}{ SFA } & \multicolumn{2}{|c|}{ MUFA } & \multicolumn{2}{|c|}{ PUFA } & \multicolumn{2}{|l|}{ EPA } & \multicolumn{2}{|l|}{ DHA } & \multicolumn{2}{|l|}{ ARA } & \multicolumn{2}{|l|}{ ALA } & \multicolumn{2}{|l|}{ LIN } & \multicolumn{2}{|l|}{ BAFA } & \multicolumn{2}{|l|}{$\omega 3: \omega 6$} & \multicolumn{2}{|c|}{ DHA:EPA } \\
\hline & Mean & $\pm \mathrm{SE}$ & Mean & $\pm \mathrm{SE}$ & Mean & $\pm \mathrm{SE}$ & $\pm \mathrm{SE}$ & $\pm \mathrm{SE}$ & Mean & $\pm \mathrm{SE}$ & Mean & $\pm \mathrm{SE}$ & Mean & $\pm \mathrm{SE}$ & Mean & $\pm \mathrm{SE}$ & Mean & $\pm \mathrm{SE}$ & Mean & $\pm \mathrm{SE}$ & Mean & $\pm \mathrm{SE}$ \\
\hline G. holbrooki & 42.0 & 1.3 & 26.2 & 2.0 & 29.3 & 2.4 & 1.3 & 0.2 & 6.5 & 1.2 & 5.0 & 0.7 & 3.0 & 0.3 & 6.5 & 0.4 & 9.6 & 1.0 & 0.9 & 0.1 & 5.2 & 0.7 \\
\hline A. thienemanni & 37.4 & 1.9 & 36.7 & 1.6 & 25.8 & 1.9 & 4.4 & 0.3 & 0.2 & 0.0 & 3.6 & 0.3 & 4.6 & 0.3 & 12.0 & 1.2 & 4.9 & 0.5 & 0.6 & 0.0 & 0.0 & 0.0 \\
\hline Planktonic zooplankton & 64.0 & 0.6 & 11.8 & 0.3 & 11.2 & 0.7 & 0.9 & 0.1 & 0.4 & 0.0 & 0.0 & 0.0 & 3.8 & 0.3 & 1.4 & 0.1 & 15.3 & 0.7 & 2.5 & 0.2 & 0.5 & 0.1 \\
\hline Benthic zooplankton & 62.5 & 1.3 & 12.3 & 0.5 & 13.3 & 1.1 & 0.8 & 0.2 & 0.4 & 0.1 & 0.0 & 0.0 & 6.1 & 0.5 & 1.4 & 0.1 & 14.5 & 0.6 & 3.8 & 0.6 & 0.7 & 0.2 \\
\hline Seston & 62.2 & 1.7 & 18.7 & 0.8 & 16.0 & 1.5 & 1.2 & 0.4 & 0.3 & 0.1 & 0.9 & 0.4 & 4.6 & 0.6 & 3.2 & 0.3 & 8.8 & 1.2 & 1.4 & 0.2 & 0.2 & 0.1 \\
\hline Periphyton & 57.8 & 1.2 & 25.7 & 1.4 & 14.3 & 0.7 & 0.8 & 0.1 & 0.1 & 0.0 & 0.7 & 0.1 & 4.1 & 0.6 & 3.7 & 0.3 & 7.2 & 1.2 & 1.2 & 0.2 & 0.1 & 0.0 \\
\hline Biofilm & 52.3 & 1.2 & 29.3 & 1.9 & 14.7 & 0.9 & 1.1 & 0.2 & 0.4 & 0.1 & 0.7 & 0.1 & 3.1 & 0.5 & 3.8 & 0.4 & 12.4 & 1.6 & 1.3 & 0.1 & 0.3 & 0.1 \\
\hline Macrophytes & 38.1 & 3.4 & 9.0 & 1.6 & 52.5 & 4.9 & 0.2 & 0.1 & 0.1 & 0.1 & 0.3 & 0.2 & 34.1 & 4.4 & 14.6 & 1.5 & 2.5 & 0.8 & 2.1 & 0.2 & 0.3 & 0.2 \\
\hline Benthic Litter & 49.2 & 2.3 & 10.2 & 0.9 & 11.3 & 1.2 & 0.1 & 0.1 & 0.0 & 0.0 & 0.1 & 0.1 & 5.1 & 0.9 & 5.1 & 0.5 & 26.2 & 2.5 & 0.9 & 0.1 & 0.0 & 0.0 \\
\hline Terrestrial litter & 46.7 & 0.8 & 8.1 & 0.7 & 10.2 & 0.8 & 0.0 & 0.0 & 0.0 & 0.0 & 0.0 & 0.0 & 2.4 & 0.5 & 6.0 & 0.7 & 32.8 & 2.0 & 0.4 & 0.1 & 0.0 & 0.0 \\
\hline
\end{tabular}

* Highest and lowest mean value for each column in bold 
Table 4: Results of similarity percentage analysis (SIMPER) of fatty acid data for sources and animals; data not transformed prior to analysis. Essential fatty acids docosahexaenoic (DHA), arachidonic (ARA), alpha-linolenic (ALA) and linoleic acid (LIN) included in parenthesis beside relevant lipid name.

\begin{tabular}{|c|c|c|c|c|c|c|c|}
\hline Source & Fatty acid & $\begin{array}{l}\text { Average } \\
\text { abundance }\end{array}$ & $\begin{array}{l}\text { Contribution to } \\
\text { similarity (\%) }\end{array}$ & Animal & Fatty acid & $\begin{array}{l}\text { Average } \\
\text { abundance }\end{array}$ & $\begin{array}{l}\text { Contribution to } \\
\text { similarity (\%) }\end{array}$ \\
\hline \multirow{7}{*}{$\begin{array}{l}\text { Seston } \\
\text { (85\% average } \\
\text { similarity) }\end{array}$} & $16: 0$ & 29.9 & 33.5 & \multirow{7}{*}{$\begin{array}{l}\text { G. holbrooki } \\
\text { (88\% average } \\
\text { similarity) }\end{array}$} & $16: 0$ & 22.9 & 25.2 \\
\hline & $18: 0$ & 9.6 & 10.3 & & $18: 1 \omega 9$ & 16.3 & 16.2 \\
\hline & $18: 1 \omega 9$ & 8.4 & 7.9 & & $18: 0$ & 9.6 & 10.6 \\
\hline & $14: 0$ & 6.3 & 6.7 & & $18: 2 \omega 6(\mathrm{LIN})$ & 6.5 & 6.7 \\
\hline & $18: 3 \omega 3$ (ALA) & 4.6 & 4.8 & & $22: 6 \omega 3$ (DHA) & 6.5 & 5.8 \\
\hline & $16: 1 \omega 7$ & 4.1 & 4.2 & & $20: 4 \omega 6$ (ARA) & 5.0 & 4.5 \\
\hline & $18: 2 \omega 6(\mathrm{LIN})$ & 3.2 & 3.4 & & $18: 1 \omega 7$ & 3.5 & 3.7 \\
\hline \multirow{6}{*}{$\begin{array}{l}\text { Periphyton } \\
\text { (81\% average } \\
\text { similarity) }\end{array}$} & $16: 0$ & 34.8 & 38.5 & \multirow{4}{*}{$\begin{array}{l}\text { A. thienemanni } \\
\text { (87\% average } \\
\text { similarity) }\end{array}$} & $18: 1 \omega 9$ & 27.9 & 28.4 \\
\hline & $18: 1 \omega 9$ & 8.6 & 8.4 & & $16: 0$ & 25.9 & 27.4 \\
\hline & $16: 1 \omega 7$ & 9.0 & 8.1 & & $18: 2 \omega 6(\mathrm{LIN})$ & 12.0 & 11.4 \\
\hline & 18:0 & 6.8 & 7.4 & & $18: 0$ & 6.2 & 6.4 \\
\hline & $14: 0$ & 5.7 & 6.3 & \multirow{6}{*}{$\begin{array}{l}\text { Pelagic zooplankton } \\
\text { (90\% average } \\
\text { similarity) }\end{array}$} & $16: 0$ & 24.9 & 26.4 \\
\hline & $18: 2 \omega 6(\mathrm{LIN})$ & 3.7 & 3.8 & & 18:0 & 17.0 & 17.6 \\
\hline \multirow{7}{*}{$\begin{array}{l}\text { Biofilm } \\
\text { (85\% average } \\
\text { similarity) }\end{array}$} & $16: 0$ & 29.6 & 33.4 & & $10: 02-\mathrm{OH}$ & 11.4 & 11.3 \\
\hline & $18: 1 \omega 9$ & 9.7 & 9.6 & & $18: 1 \omega 9$ & 6.9 & 7.2 \\
\hline & $16: 1 \omega 7$ & 9.8 & 9.2 & & $22: 0$ & 5.2 & 5.2 \\
\hline & 18:0 & 7.3 & 8.0 & & $14: 0$ & 4.8 & 4.8 \\
\hline & $18: 1 \omega 7$ & 6.5 & 5.5 & \multirow{6}{*}{$\begin{array}{l}\text { Benthic } \\
\text { zooplankton } \\
\text { (88\% average } \\
\text { similarity) }\end{array}$} & $16: 0$ & 24.8 & 26.8 \\
\hline & $14: 0$ & 4.4 & 4.3 & & 18:0 & 16.8 & 17.7 \\
\hline & $18: 2 \omega 6$ (LIN) & 3.8 & 3.8 & & 10:0 2-OH & 10.5 & 10.2 \\
\hline \multirow{3}{*}{$\begin{array}{l}\text { Macrophytes } \\
\text { (84\% average } \\
\text { similarity) }\end{array}$} & $18: 3 \omega 3$ (ALA) & 37.5 & 36.5 & & $18: 1 \omega 9$ & 6.8 & 7.3 \\
\hline & $16: 0$ & 25.1 & 27.0 & & $18: 3 \omega 3$ (ALA) & 6.1 & 5.9 \\
\hline & $18: 2 \omega 6(\mathrm{LIN})$ & 15.9 & 18.0 & & $22: 0$ & 5.1 & 5.3 \\
\hline \multirow{2}{*}{$\begin{array}{l}\text { Benthic litter } \\
\text { ( } 81 \% \text { average } \\
\text { similarity) }\end{array}$} & $16: 0$ & 21.9 & 24.6 & & & & \\
\hline & Unknown 1* & 15.6 & 15.9 & & & & \\
\hline
\end{tabular}




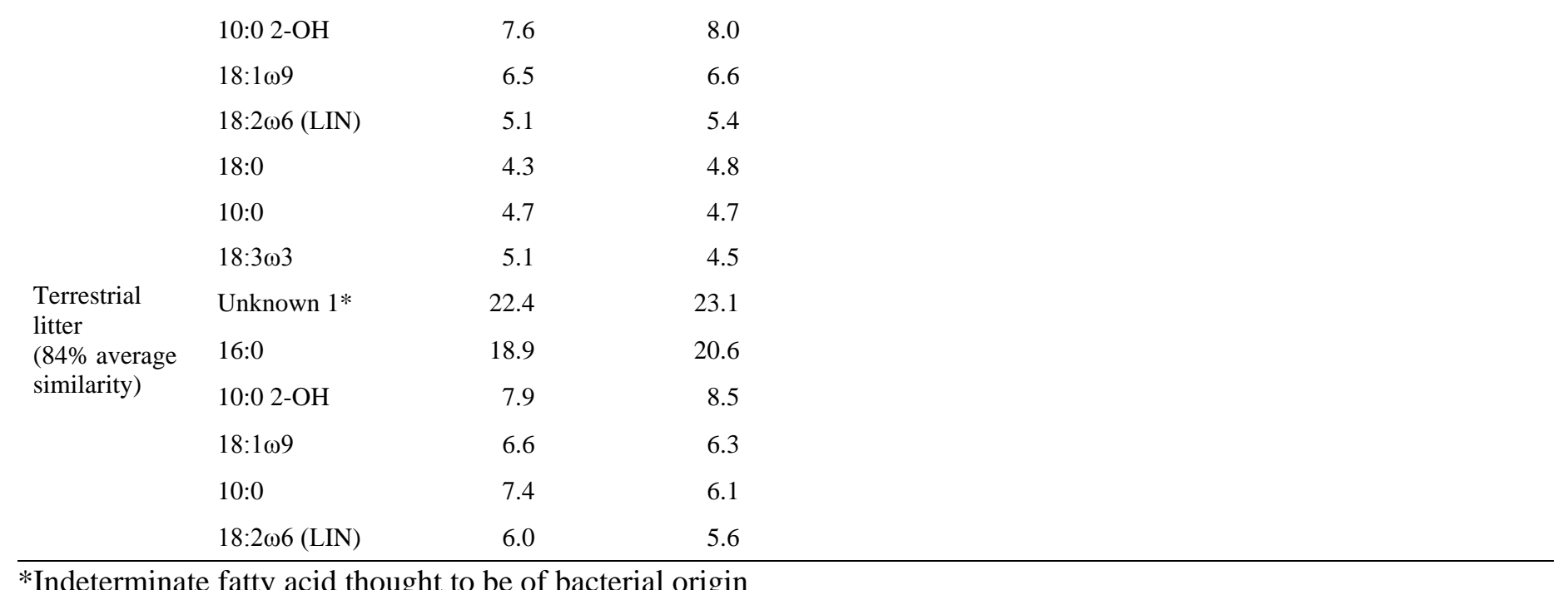

*Indeterminate fatty acid thought to be of bacterial origin 


\section{University Library}

\section{- M M N E R VA A gateway to Melbourne's research publications}

Minerva Access is the Institutional Repository of The University of Melbourne

Author/s:

Mclnerney, PJ;Holt, G;Lester, RE;Thompson, RM;Robson, B;Ryder, DS;Bond, NR;Baldwin, DS;Gawne, B;Petrie, R

Title:

Basal resource quality and energy sources in three habitats of a lowland river ecosystem

Date:

2020-07-05

Citation:

Mclnerney, P. J., Holt, G., Lester, R. E., Thompson, R. M., Robson, B., Ryder, D. S., Bond, N. R., Baldwin, D. S., Gawne, B. \& Petrie, R. (2020). Basal resource quality and energy sources in three habitats of a lowland river ecosystem. LIMNOLOGY AND OCEANOGRAPHY, 65 (11), pp.2757-2771. https://doi.org/10.1002//no.11548.

Persistent Link:

http://hdl.handle.net/11343/286972 